\title{
FÁCIES, ICNOFÓSSEIS, PALEOCORRENTES E SISTEMAS DEPOSICIONAIS DA FORMAÇÃO FURNAS NO FLANCO SUDESTE DA BACIA DO PARANÁ
}

\author{
MÁRIO LUÍS ASSINE
}

\begin{abstract}
FACIES, TRACE FOSSILS, PALEOCURRENTS AND DEPOSITIONAL SYSTEMS OF THE FURNAS FORMATION SOUTHEAST PARANA BASIN. The origin of the psamitic Late Silurian(?) to Early Devonian Furnas Formation is a matter of controversy. Although body fossils hás never been found yet, trace fossils are present throughout the unit. In order to interpret its depositional paleoenvironment, a study was carried out at the southeastern outcrop belt of Devonian sequence of the Paraná basin. Based on different fácies associations the Furnas Formation is herein subdivided into three units. The lower unit is made up of sandstones and conglomerates deposited in large alluvial-coastal plains. An westward paleoslope with source-area at east and an approximate north-south paleoshoreline were deduced from paleocurrent data. The fine to coarse-grained, cross-bedded sandstones of the middle unit are arranged in cosets separated by shale beds. Rusophycus and Cruziana trace fossils support a marine origin for the middle unit. Paleoflow toward southwest are oriented obliquely with respect to the shoreline and probably had been produced by tidal currents. The cross-bedded coarse-grained sandstones of the upper unit, bearing bimodal to polimodal paleocurrents patterns, are interpreted as subaqueous sandwave and dune deposits formed by tidal currents. Winnowed pebble lags are common at the top of cosets being considered product of tidal currents enhanced by storm waves. The type-section is located in the Guartelá canyon (lapó river), where the Furnas Formation is $250 \mathrm{~m}$ thick. The three units are recognized in well logs and can be used in regional stratigraphic correlation.
\end{abstract}

Keywords: Furnas Formation, Devonian, paleocurrents, icnofossils, sedimentology, Paraná basin

RESUMO A origem da Formação Furnas (Neo-Siluriano?/Eodevoniano) é assunto controverso. Com o objetivo de interpretar o paleoambiente deposicional, foi realizada análise de fácies na faixa aflorante no flanco sudeste da bacia do Paraná, onde a Formação Furnas foi subdividida em três unidades, caracterizadas por associacões faciológicas distintas. A unidade inferior é constituída por arenitos e conglomerados depositados em extensas planícies aluviais costeiras. Paleocorrentes deduzidas das camadas frontais dos estratos cruzados permitiram deduzir paleomergulho deposicional para oeste, área-fonte a leste e paleolinha de costa aproximadamente norte-sul. A unidade média é constituída por camadas de arenitos com estratificação cruzada separadas por níveis pelíticos, sob os quais é comum a existência de icnofósseis. A presença dos icnogêneros Rusophycus e Cruziana, traços fósseis que em unidades eo- a mesopaleozóicas são atribuídos à atividade de trilobitas, corrobora a interpretação de origem marinha para estes arenitos. Paleocorrentes dirigidas para sudoeste são consideradas produto da migracão de barras por correntes de maré obliquas à linha de costa. A unidade superior caracteriza-se pela presença de depósitos residuais de seixos, delgados e extensos, que ocorrem como pavimentos separando cosets de arenito com estratificação cruzada, cujas paleocorrentes apresentam grande dispersão de dados e padrões bimodais a polimodais. Os depósitos residuais foram produzidos pelo joeiramento dos sedimentos do fundo com o aumento da amplitude das ondas durante tempestades, numa plataforma arenosa rasa dominada por correntes de maré. A seção-tipo das três unidades é a do canyon do Guartelá (rio lapó), onde foi levantado um perfil estratigráfico vertical da Formação Furnas com cerca de $250 \mathrm{~m}$ de espessura. As três unidades foram reconhecidas em perfis de poços no oeste do Estado do Paraná, evidenciando que a subdivisão proposta tem expressão regional.

Palavras-chaves: Formação Furnas, Devoniano, paleocorrentes, icnofósseis, sedimentologia, Bacia do Paraná

INTRODUÇÃO A Formação Furnas é uma extensa unidade siliciclástica da Bacia do Paraná, constituída por arenitos quartzosos brancos, de granulação média a grossa, feldspáticos e/ou caulínicos, mal selecionados, portadores de estratificação cruzada, aos quais se interestratificam delgados níveis de conglomerados, sobretudo na porção basal. Apresenta geometria tabular e pequena variabilidade de espessura, com possança no geral entre 250 e $300 \mathrm{~m}$, somente alterada nas proximidades dos limites de ocorrência, quando indica bordas erosivas (Assine 1996).

A Formação Furnas sobrepõe discordantemente unidades de diferentes naturezas e idades, desde rochas magmáticas e metamórficas do embasamento cristalino pré-cambriano/eopaleozóico até, rochas ordovício-silurianas do Grupo Rio Ivaí (Assine et al. 1994). É sobreposta pelos estratos devonianos da Formação Ponta Grossa (Meso- a Neodevoniano), que com ela compõem o Grupo Paraná.

À Formação Furnas tem sido atribuída idade eodevoniana em funcão do contato concordante com os folhelhos marinhos superpostos da Formação Ponta Grossa (Emsiano / Fammeniano), materializado pelas Camadas de Transição no seu topo (Petri 1948). Corrobora esta interpretação a identificação de palinomorfos praguianos (Dino \& Rodrigues 1995), recuperados de um nível pelítico intercalado nos arenitos da parte superior da Formação Furnas, no Município de Jaguariaíva (PR). Com relação ao início da sedimentação, é possível que tenha ocorrido já a partir do final do Siluriano (Pridoliano), como sugeriu Borghi (1993), mas ainda não se dispõe de dados que permitam estabelecer com precisão a idade dos estratos de sua porção inferior.

A interpretação do seu paleoambiente deposicional é matéria controversa. Para a maioria dos pesquisadores a unidade foi depositada em ambiente marinho raso (Petri 1948, Sanford \& Lange 1960 , Bigarella et al. 1966, Lange \& Petri 1967, Bigarella 1973, Petri \& Fúlfaro 1983, Borghi 1993). Outros autores postularam origem fluvial (Northfleet et al. 1969, Schneider et al 1974, Andrade \& Camarço 1980, Melo 1988, Zalán et al. 1987). Numa outra vertente, Bergamaschi (1992) e Assine et al. (1994) consideraram que a unidade é faciologicamente complexa, produto da associação de fácies deltaicas e marinhas plataformais.

A reconstituição paleoambiental da Formação Furnas, como a de outras unidades psamíticas eo- a mesopaleozóicas (Chandler 1988), tem sido problemática em decorrência da pobreza de fósseis, da escassez de pelitos intercalados, da grande area de ocorrência e, sobretudo, da inexistência de ambientes sedimentares análogos no Recente

Para contribuir na elucidacão da questão relativa ao paleoambiente deposicional da Formação Furnas, foram estudados e descritos cerca de cem afloramentos no flanco sudeste da Bacia do Paraná (PR e SP), buscando-se analisar conjuntamente as associações de fácies, os icnofósseis e as paleocorrentes. Neste trabalho são feitas referências e apresentados dados de 42 afloramentos representativos da unidade na área(Fig. 1).

FÁCIES SEDIMENTARES Análise detalhada na faixa de afloramentos (excluindo-se as Camadas de Transição) permitiu a caracterização de três associações faciológicas distintas que se sucedem na vertical, referidas como unidades inferior, média e superior. Dentre as seções levantadas, a do canyon do Guartelá (rio lapó) é a mais representativa, apresentando exposição contínua de cerca de $250 \mathrm{~m}$, desde o contato basal com rochas vulcânicas do Grupo Castro até as Camadas de Transição no topo da Formação Furnas (Figs. 2 e 3), sendo considerada seção-tipo das três unidades.

Unidade inferior Compreende arenitos médios a muito grossos, feldspáticos e/ou caulínicos, com grãos angulosos a subangulosos, dispostos em camadas (sets) com geometria tabular, lenticular e cuneiforme (Fig. 4-A), espessuras entre 0,5 e $1,5 \mathrm{~m}$ e estratificações cruzadas planar e tangencial na base, aos quais se intercalam arenitos conglomeráticos e conglomerados quartzosos de granulação fina, com clastos subangulosos no geral menores que $2 \mathrm{~cm}$. Os conglomerados apresentam-se em camadas de pequena espessura (no máximo $1 \mathrm{~m}$ ), geometria lenticular a irregular (Fig. 4-B), padrão de granodecrescência ascendente, sendo texturalmente maciços ou com estratificação plano-paralela mal definida (Bigarella et al. 1966).

$\mathrm{Na}$ base da unidade há concentração de seixos e calhaus, ocorrendo por vezes conglomerados basais com espessuras no geral menores que $2 \mathrm{~m}$, matriz arenosa e clastos com diâmetro máximo constatado de 12 cm (Fig. 4-C). O conjunto é granodecrescente para o topo, com redução progressiva dos termos conglomeráticos, transicionando para os arenitos da unidade média.

Disposta imediatamente acima da discordância com as unidades subjacentes, em contatos planos e bem definidos, é a unidade da Formação Furnas que apresenta maior resistência à erosão, formando relevos escarpados ao longo das faixas de afloramento (Fig. 4-D). 


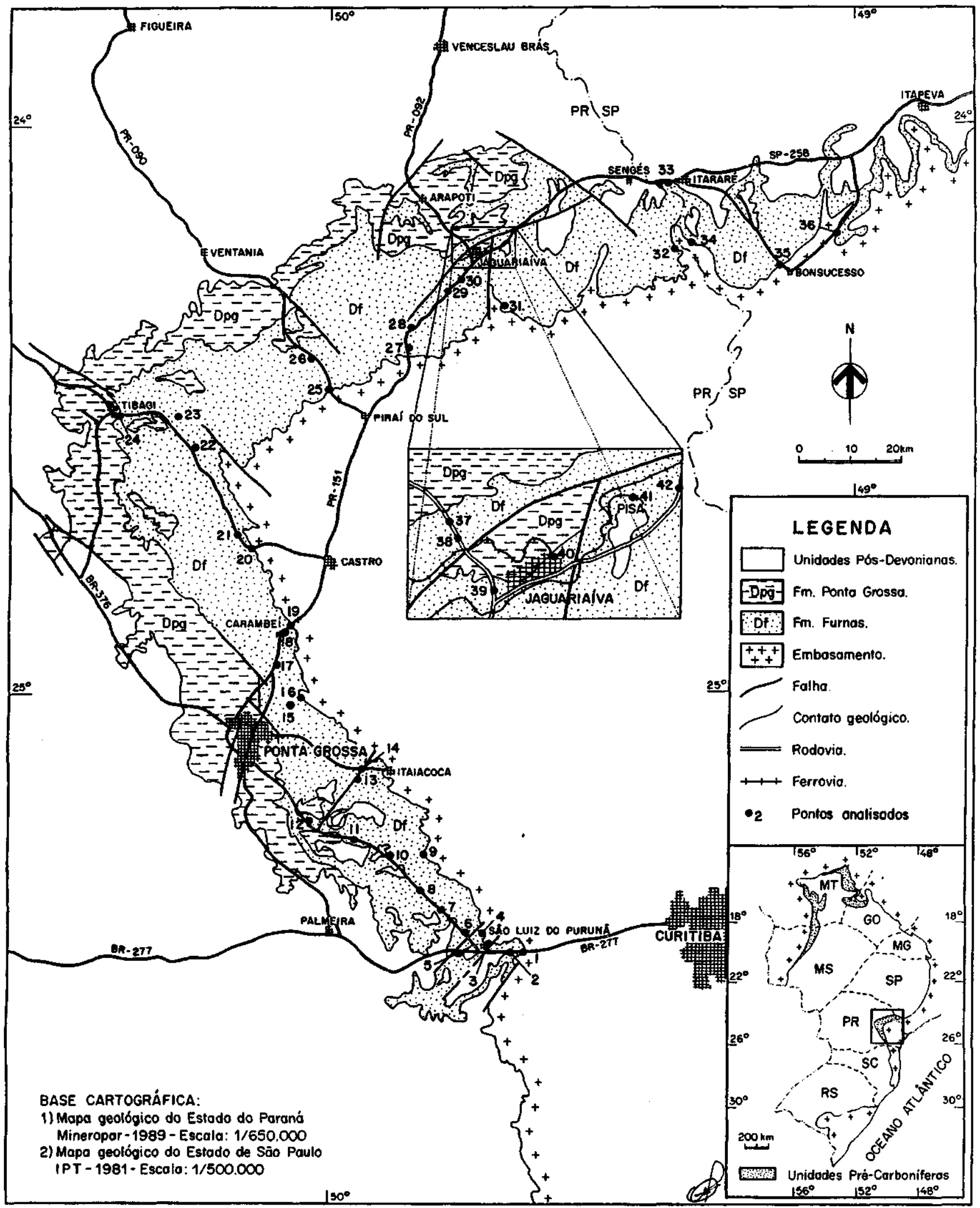

Figura J - Faixa aflorante da Formação Furnas no flanco sudeste da bacia, com indicação dos pontos analisados

Unidade média Arenitos finos a grossos, que se apresentam dispostos em camadas tabulares e/ou cuneiformes, com 0,5 a 2,0 m de espessura e estratificação cruzada planar, por vezes com sentidos contrários de fluxo (Fig. 5-A). As camadas frontais dos estratos cruzados (foresets) podem ser tangenciais na base, gradando para arenitos muito finos e siltitos ricos em moscovita em camadas com acamamento ondulado (wavy bedding) (Fig. 5-B). Secundariamente, na associação estão presentes também estratificações cruzadas acanaladas. Geometrias sigmóides também ocorrem, definindo corpos arenosos separados por lâminas de argila (Fig. 5-C). Em intervalos de granulação mais fina, os estratos cruzados podem apresentar lâminas de argila entre as camadas frontais, estrutura flaser e intraclastos de 


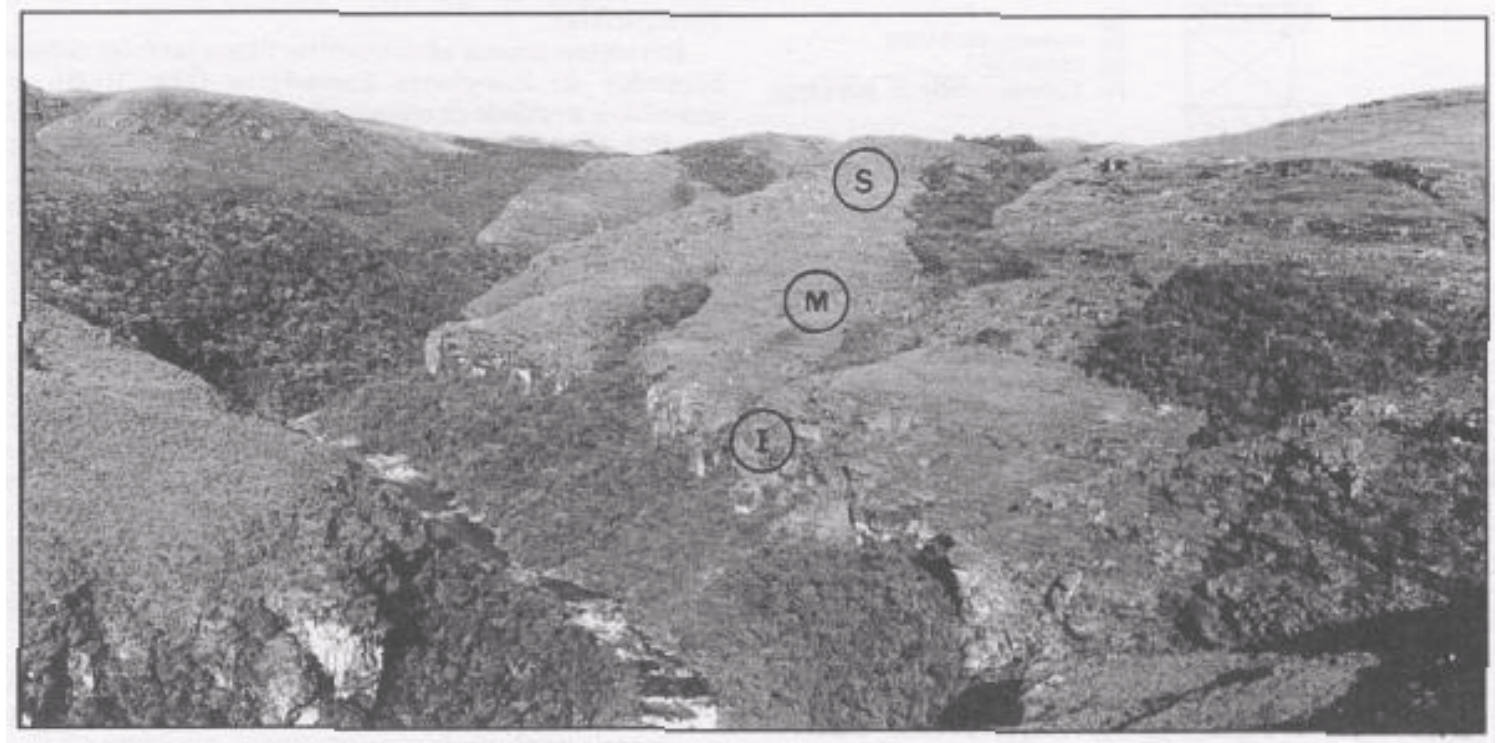

Figura 2 - Canyon do Guartelá (rio lapó), com indicação das unidades inferior (I), média (M) e superior (S) da Formação Furnas

argila (rip-up clasts). Localmente, em arenitos finos a médios, podem ser observadas estruturas geradas pela ação de ondas.

O empilhamento de diversas camadas com estratificação cruzada forma cosets, cujo topo é normalmente truncado por superficies de reativação. As camadas são normalmente paralelas aos limites dos cosets, mas podem também ser separadas por superficies de acresção de baixo ângulo $\left(<10^{\circ}\right)$ delineando formas de leito complexas e de maior amplitude. Uma excelente exposição destas feições pode ser observada no ponto 25 (PR-090, entre as cidades de Piraí e Ventania), em corte de estrada na escarpa do segundo planalto paranaense. Embora não comuns, geometrias originais ficaram preservadas, desenhando formas de leito de até $5 \mathrm{~m}$ de espessura (Fig. 5-D).

Os cosets são separados por intercalações de siltitos e folhelhos de cores verde clara a branca, com espessuras de poucos milímetros até camadas com mais de dois metros. Sob os níveis pelíticos é comum a presença de traços fósseis paralelos ao acamamento. Esta intercalação de níveis finos entre os bancos arenosos se reflete na morfologia, dando origem a encostas caracterizadas por degraus.

Unidade superior Compõe-se de arenitos médios a muito grossos, dispostos em camadas com estratificações cruzadas tabular e acanalada, com espessuras que variam de 0,5 a 7,0 m (Fig. 6-A). Alguns estratos cruzados apresentam lâminas de argila e deformação penecontemporânea nas camadas frontais. Sentidos opostos de fluxo foram observados em alguns afloramentos, caracterizando estratificações cruzadas espinha-de-peixe (Fig. 6-B). A unidade caracteriza-se pela existência de depósitos residuais de seixos (lags), delgados e extensos, que ocorrem em superfícies erosivas planares separando camadas com estratificação cruzada (Fig. 6-C). Os seixos são quartzosos, arredondados, assimétricos (muitos em forma de bastão), ocorrendo também calhaus com diâmetro máximo constatado de 15 $\mathrm{cm}$. Os níveis estendem-se muitas vezes por centenas de metros, tendo sido um nível de conglomerado rastreado lateralmente por cerca de $1500 \mathrm{~m}$ no canyon do Guartelá (ponto 23). Frequentemente constituem superfícies com clastos dispersos sem contato físico entre si (Fig. 6-D), mas, por vezes, formam camadas de conglomerados quartzosos clastosuportados com até $0,5 \mathrm{~m}$ de espessura. Escassos e pouco espessos níveis síltico-argilosos por vezes recobrem os pavimentos de seixos, evidenciando que estes são feições de topo e não depósitos basais. Na parte superior da Formação Furnas, localmente acham-se presentes arenitos muito finos com estratificação cruzada hummocky, muitas vezes portadores de restos de vegetais vasculares primitivos (Fig. 6-E), classificados como Horneophyton, Zosterophyüum e Cooksonia e descritos em detalhe por Mussa et al. (1996). Associados a estes arenitos, existem raras ocorrências de fácies heterolíticas, definidas pela interestratificação de folhelhos sílticos cinza médio a escuro e arenitos muito finos, destacando-se a do ramal ferroviário de acesso à indústria Pisa (Fig. 6-F, ponto 41), cujo conteúdo palinológico permitiu a Dino e Rodrigues (1995) posicionar o intervalo no Praguiano.
PALEOCORRENTES Padrões de paleocorrentes diferentes foram observados para as três unidades na seção-tipo levantada no canyon do lapó/Guartelá (Fig. 2). Mas, seriam eles representativos de toda a faixa de afloramentos do flanco sudeste da bacia, tendo conotação paleogeográfica regional?

Para verificar a hipótese, os diferentes afloramentos do flanco sudeste da bacia foram classificados segundo a divisão estratigráfica proposta. A seguir, os diagramas em roseta dos pontos analisados, foram agrupados segundo as três unidades e lançados em três diferentes mapas. Tal procedimento permitiu também posicionar e analisar conjuntamente os pontos de Bigarella et al. (1966).

A análise dos mapas gerados (Figs. 7, 8 e 9) permitiu deduzir que cada uma das unidades de fato apresenta padrão de paleocorrentes distinto. A unidade inferior é caracterizada por paleocorrentes uni a bimodais com paleofluxo principal para oeste (média aritmética dos vetores médios para o azimute $274^{\circ}$ ).

Na unidade média, embora a dispersão dos dados seja maior, os diagramas também apresentam padrão uni a bimodal, mas com sentido de transporte nitidamente para sudoeste (média aritmética dos vetores médios para o azimute $218^{\circ}$ ).

Na unidade superior a dispersão dos dados é maior ainda, predominando padrões bi a polimodais. Nestes casos a média não foi considerada por não ter significado geológico, conforme discutido em Selley (1982). Valores de variância acima de 4000 foram calculados para muitas das distribuições apresentadas.

ICNOFÓSSEIS Embora ainda não tenham sido encontrados organismos ou moldes fósseis na Formação Furnas, os icnofósseis são abundantes. Após o trabalho pioneiro de Lange (1942) poucos estudos foram realizados sobre o assunto. Os estudos foram retomados por José H. G. Ciguel, cujo trágico falecimento, durante trabalhos de campo, impediu-nos de conhecer a maior parte de suas descobertas, relatadas apenas em breves comunicações, nas quais informa a ocorrência de grande diversidade de formas (por exemplo: Ciguel \& Acenolaza, 1986). Uma síntese sobre a evolução dos conhecimentos a respeito dos icnofósseis da Formação Furnas, com descrição das formas reconhecidas, pode ser encontrada em Fernandes (1996).

Predominam amplamente traços suborizontais paralelos ao acamamento, principalmente na unidade média, constituindo formas em epirrelevo côncavo e/ou convexo, desenvolvidas no topo das camadas de arenito com estratificação cruzada (Fig. 1 O-A). Os icnofósseis encontram-se melhor preservados em litologias de granulometria fina, mas a natureza do substrato não é fator limitante, tendo sido observados traços fósseis até mesmo em níveis conglomeráticos. A preservação é melhor quando tais superficies são recobertas por lâminas ou camadas pelíticas.

Traços levemente sinuosos e estreitos (1 a $2 \mathrm{~cm}$ de largura), dos icnogêneros Paleophycus e Planolites, são os mais comuns. Estes 


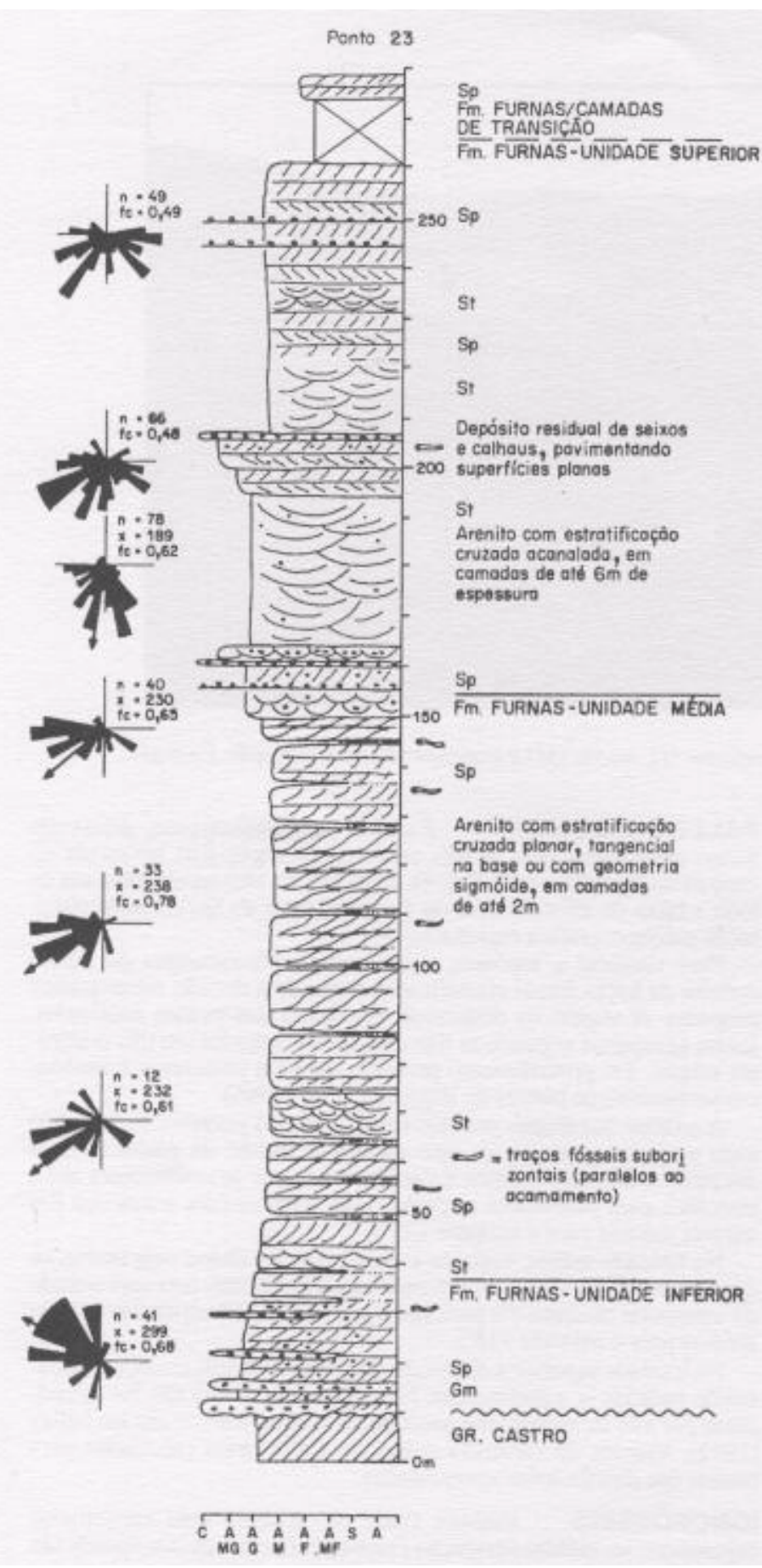

Figura 3 - Perfil estratigráfico vertical da Formação Furnas no canyon do Guartelá (rio lapó), em Tibagi-PR. (ponto 23; localização: ver figura 1). Código de fácies: $G m=$ conglomerado maciço; $S p=$ arenito com estratificação cruzada planar; $S t=$ arenito com estratificação cruzada acanalada)

traços registram hábitos de alimentação e/ou deslocamento, tendo sido produzidos por escavação endoestratal. São muito abundantes em alguns níveis, encontrando-se presentes sobretudo no topo de coseis, mas foram observados também em algumas camadas frontais de estratos cruzados, indicando hábitos oportunistas.

Também comuns são traços bilobados lineares e levemente sinuosos. Foram descritos pela primeira vez na Formação Furnas por Lange (1942), que os denominou Fraena fumai. Posteriormente, Lange \& Petri (1967) referiram-se a eles como Rouaultia fumai, não apresentando os motivos que os levaram à mudança na sistemática. Fernandes \& Netto (1985) e Ciguel \& Acenolaza (1991), em breves comunicações, reinterpretam-nos como traços de deslocamento de moluscos, pertencentes ao icnogênero Didymaulichnus. Borghi \& Schubert (1992) propuseram que tais traços constituem um novo icnogênero: Furnasichnus.

Em alguns poucos afloramentos, foram também constatados traços bilobados do icnogênero Rusophycus (Fig. 10-B), normalmente atribuído à atividade de repouso de trilobitas. Com geometrias grosseiramente elipsoidais e larguras entre 0,5 a $2,0 \mathrm{~cm}$, frequentemente apresentam-se bilobados em apenas uma das extremidades, delineando perfil vertical assimétrico, mais profundo do lado não bilobado. Os traços não apresentam ornamentação nos lóbulos, cuja preservação pode ter sido dificultada pela natureza do substrato. Rusophycus foi anteriormente relatado na Formação Furnas por Ciguel \& Acenolaza (1986), Bergamaschi (1992), Borghi (1993) e Assine \& Gois (1996).

Associados aos Rusophycus ocorrem traços de deslocamento, bilobados e retilíneos, com larguras de aproximadamente $2,0 \mathrm{~cm}$ e comprimentos entre 10 e $30 \mathrm{~cm}$, também sem ornamentação evidente nos lóbulos (Fig. 10-C). Há, mesmo, exemplos de traços curtos e mais profundos conectados por traços bilobados lineares menos profundos (Fig. 10-D/E). Isto demonstra que ambos os traços foram construídos pelo mesmo organismo, permitindo considerá-1 os traços pertencentes ao icnogênero Cruziana (Fig. 10-F). O icnogênero Cruziana foi anteriormente reconhecido na Formação Furnas por Ciguel \& Acenolaza (1986) e Assine \& Gois (1996).

SISTEMAS DEPOSICIONAIS As litofácies de arenitos grossos a muito grossos, a onipresença de camadas com estratificação cruzada, a existência de níveis de conglomerados, a pobreza em fácies pelíticas, a não constatação de organismos fósseis e, mesmo, a ausência de glauconita (Zalán et al. 1987), têm sido usados como critérios e argumentos, por muitos pesquisadores, para a adoção de um modelo de fácies fluvial entrelaçado (braided) como paleoambiente deposicional da Formação Furnas. Some-se a isso a inexistência de ambientes de sedimentação modernos que possam servir de modelo deposicional para uma interpretação marinha.

Alguns atributos caracterizados na análise de fácies realizada permitiram a interpretação de tratos deposicionais predominantemente marinhos para a maior parte da unidade na faixa de afloramentos do flanco sudeste da Bacia do Paraná

Arenitos grossos com estratificação cruzada e alguns níveis conglomeráticos são, da mesma forma que em ambientes fluviais entrelaçados, as litologias dominantes em sequências marinhas transgressivas. Ao contrário dos sistemas marinhos regressivos, as plataformas marinhas transgressivas são frequentemente pavimentadas com areia média a muito grossa, que podem se estender até a borda da plataforma (Swift et al. 1986, 1991). A hipótese de que arenitos grossos e cascalhes nas plataformas continentais atuais são depósitos relitos demonstrou-se inconsistente com os dados de geologia marinha, que evidenciaram o fato de que areias grossas e cascalhes vem sendo continuamente retrabalhados por correntes marinhas (Swift \& Thorne 1991, Berne et al 1998), produzindo uma gama de formas de leito de diferentes dimensões em diversas plataformas continentais atuais.

A presença de conglomerados e arenitos grossos a muito grossos não constitui, portanto, critério que permita distinguir fácies fluviais de marinhas. Vários trabalhos, como os de Nemec \& Steel (1984) e de Phillips (1984), têm evidenciado origem marinha'para fácies psamopsefiticas com estratificação cruzada, frequentemente interpretadas como fluviais.

Ressalta-se ainda que a paleolatitude era alta ao tempo da deposição da Formação Furnas, fato já destacado por Maack (1950-51), e que as plantas vasculares apenas iniciavam a colonização dos continentes. Estes dois fatos foram responsáveis pelo predomínio do intemperismo mecânico no continente, por altas taxas de denudação e por grande disponibilidade de elásticos grossos na plataforma continental à época, com a consequente pobreza em sedimentos finos. Plataformas continentais em altas latitudes são caracterizadas pelo predomínio de areias e cascalhes mesmo nos dias atuais (Hayes 1967).

Ambientes oxidantes e com alto afluxo terrígeno, como os que se interpreta para a Formação Furnas, são inibidores para a formação de glauconita autigênica (Van Houten \& Purucker 1984). Isto mostra que sua ausência não é argumento que corrobore a interpretação de uma origem fluvial. Ademais, o intervalo Neo-Siluriano / Eodevoniano é mundialmente desfavorável à acumulação de glauconita (Odin 1982).

A pobreza em estratificações cruzadas hummocky, típicas de sistemas costeiros regressivos e marinhos plataformais dominados por ondas, não deve ser usada como argumento contrário a uma origem marinha. Tal afirmativa deve-se ao fato de que a própria natureza granulométrica dos arenitos e conglomerados da Formação Furnas é um fator limitante à formação de tais estruturas, que têm sido mundial- 
A

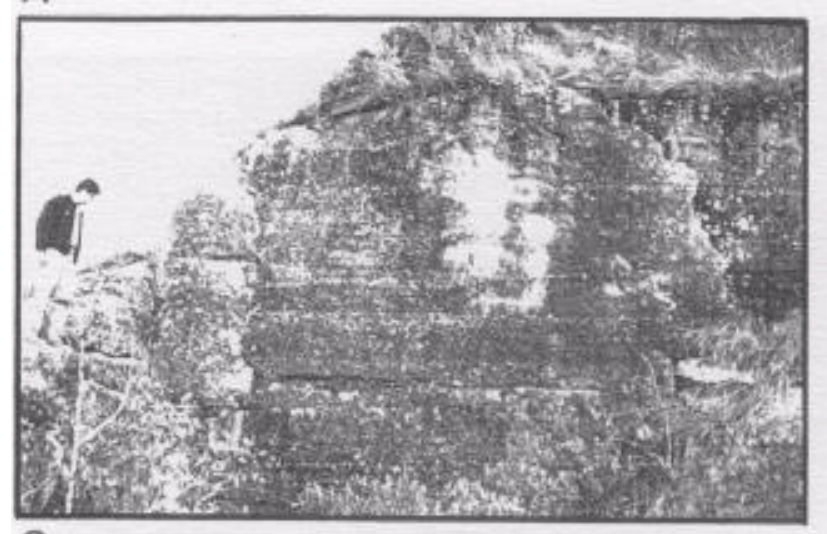

C

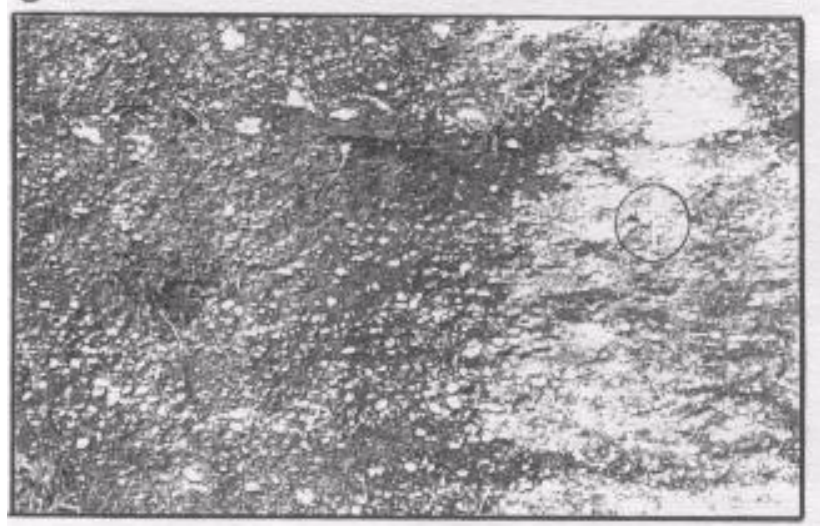

$B$

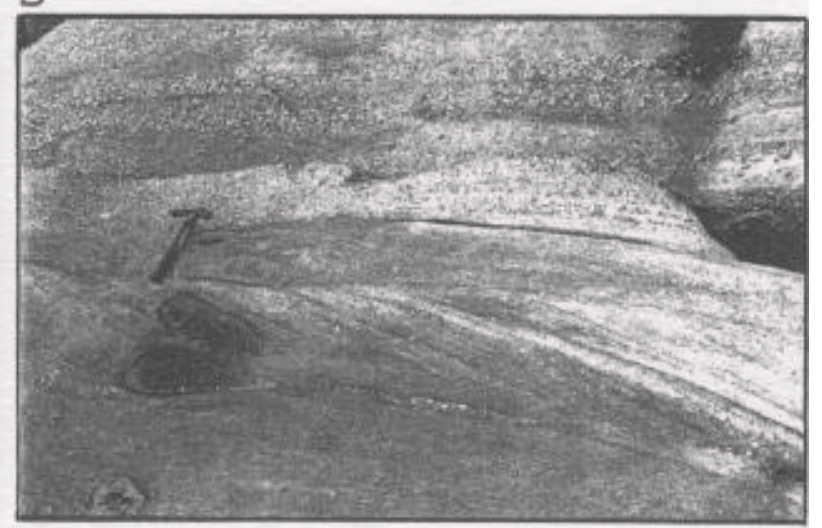

D

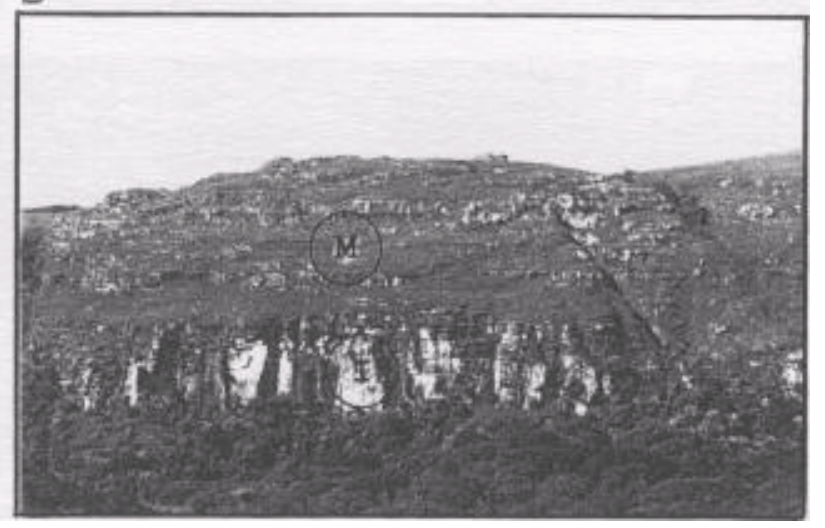

Figura 4 - Unidade inferior: A e B) associação de arenitos com estratificação cruzada e conglomerados; C) conglomerado basal; D) litologias da unidade inferior (l) são mais resistentes à erosão que as da unidade média (M), resultando em relevos escarpados

mente registradas em litologias de granulometria no máximo areia média (Duke 1990, Swift et al. 1991). Em areias mais grossas e conglomerados, as ondas tendem a produzir estratificação cruzada ou camadas gradadas (Fig. 11).

$\mathrm{Da}$ análise dos elementos arquiteturais de fácies, verificou-se que a geometria dos litossomas é caracterizada pela tabularidade das camadas, sendo subordinada a existência de formas canalizadas e estruturas de corte e preenchimento, características da arquitetura de fácies aluviais.

Por fim, se ainda não foram constatados organismos fósseis, icnofósseis são comuns na maior parte da unidade. A presença dos icnogêneros Rusophycus e Cruziana, tracos fósseis que em unidades eo- a mesopaleozóicas têm sido atribuídos à atividade de trilobitas, constitui um elemento importante na interpretação paleoambiental, pois aponta para uma origem marinha para os estratos onde ocorrem. A associação com outros traços horizontais é característica da icnofácies Cruziana, que tem sido considerada típica de ambiente marinho sublitoral, entre os níveis de base das ondas de tempo bom e das ondas de tempestade (Frey \& Pemberton 1984).

Unidade inferior As camadas conglomeráticas da base da formação são interpretadas como depósitos de canais largos e rasos em planícies aluviais costeiras, com deposição direta sobre um embasamento plano, sem evidências de vales incisos. Os conglomerados basais não ocorrem em todos os locais, como salientado anteriormente por Bigarella et al. (1966), evidenciando pontos principais de afluxo, lateralmente contíguos a outros ambientes costeiros onde interagem processos aluviais e marinhos litorâneos.

As paleocorrentes nas fácies areno-conglomeráticas desta associação mostram sentido de fluxo principal para azimute médio $274^{\circ}$ (Fig. 7), indicando mergulho deposicional para oeste, continente a leste e linha de costa aproximadamente norte-sul.

A existência de icnofósseis em arenitos conglomeráticos e conglomerados a menos de $3 \mathrm{~m}$ do contato com o embasamento (por exemplo, nos pontos 4, 9, 20 e 31), fato já relatado anteriormente por Borghi (1993), sugerem influência marinha já na parte inferior da unidade, que seria responsável por retrabalhamento dos sedimentos das planícies aluviais costeiras e pelas paleocorrentes para sudoeste observadas em algumas rosetas (Fig. 7).

Unidade média As litofácies descritas são interpretadas como produto de deposição em ambientes marinhos costa-afora dominados por marés. As fácies sedimentares nestes ambientes são influenciadas por processos não atuantes nos clássicos ambientes costeiros dominados por marés, a saber: a) marés rotacionais; b) ciclicidade de marés enchente / vazante menos evidente; c) tempestades e outros processos marinhos. Por isso, segundo Johnson \& Baldwin (1996), os critérios clássicos para reconhecer a ação de marés em regiões costeiras (estratificação cruzada espinha-de-peixe, acamamento lenticular e/ou flaser, drapes de argila, bundles de maré etc.) podem não ser diretamente aplicáveis a ambientes costa-afora onde as condições hidrodinâmicas são geralmente mais complexas.

A unidade é caracterizada pela icnofácies Cruziana, que sugere condições marinhas sublitorais. Os traços fósseis, preservados nas superfícies de topo das camadas de estratos cruzados, materializam períodos de menor energia, com diminuição acentuada ou mesmo paradas temporárias no transporte sedimentar, quando o substrato arenoso tornou-se mais estável e foi habitado por organismos que, deslocando-se no fundo, produziram abundantes pistas horizontais e extensos pavimentos bioturbados.

A cessação das correntes em muitos casos fica evidente uma vez que as superfícies, onde os icnofósseis são mais abundantes, são recobertas por camadas de siltitos e/ou folhelhos esbranquiçados e/ou esverdeados, que podem, em alguns casos, ter mais de $1,0 \mathrm{~m}$ de espessura. Paleocorrentes para sul e sudoeste (azimute médio $218^{\circ}$, Fig. 8) são interpretadas como produto de correntes oblíquas à paleolinha de costa. Anteriormente, Bigarella et al (1966) e Bigarella \& Salamuni (1967) as haviam interpretado como correntes paralelas à linha de costa. Correntes marinhas oblíquas/paralelas à costa são predominantes em uma série de exemplos atuais, como no Mar do Norte, na Baía de Hudson no Canadá e na costa leste norte-americana (Johnson \& Baldwin 1996).

O predomínio de correntes unimodais não deve ser considerado um argumento contrário à atuação de marés, pois muitas plataformas marinhas atuais são caracterizadas por correntes de maré unidirecio- 
A
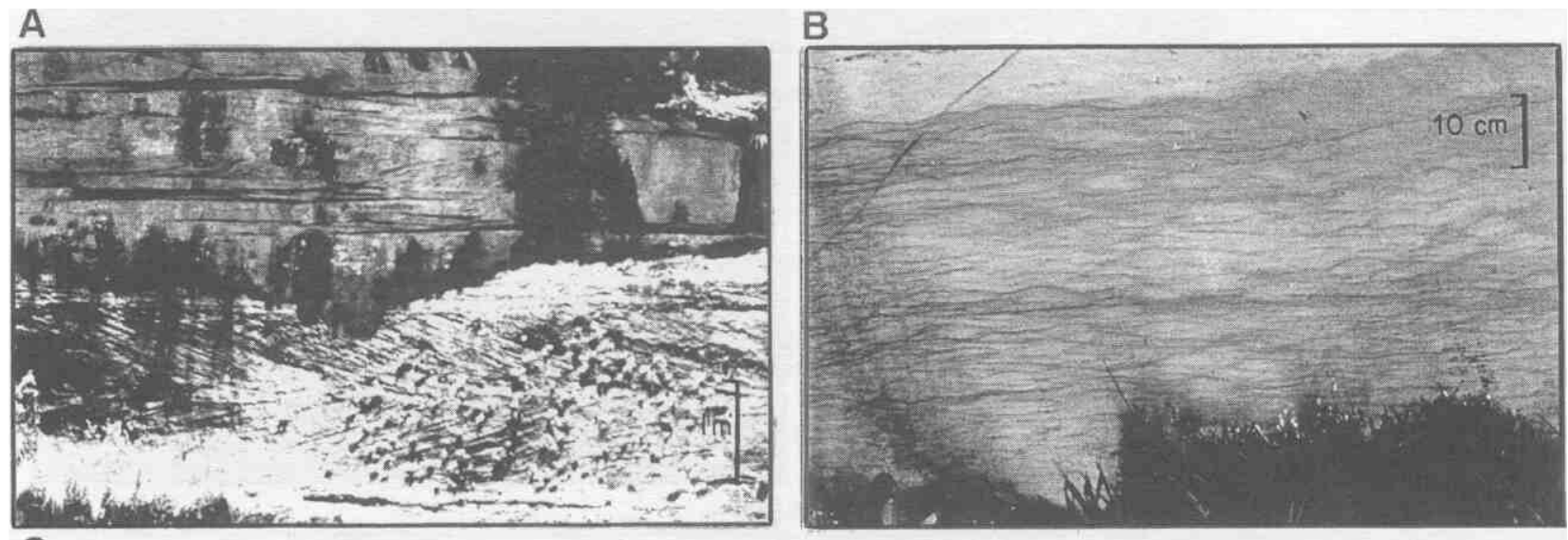

C

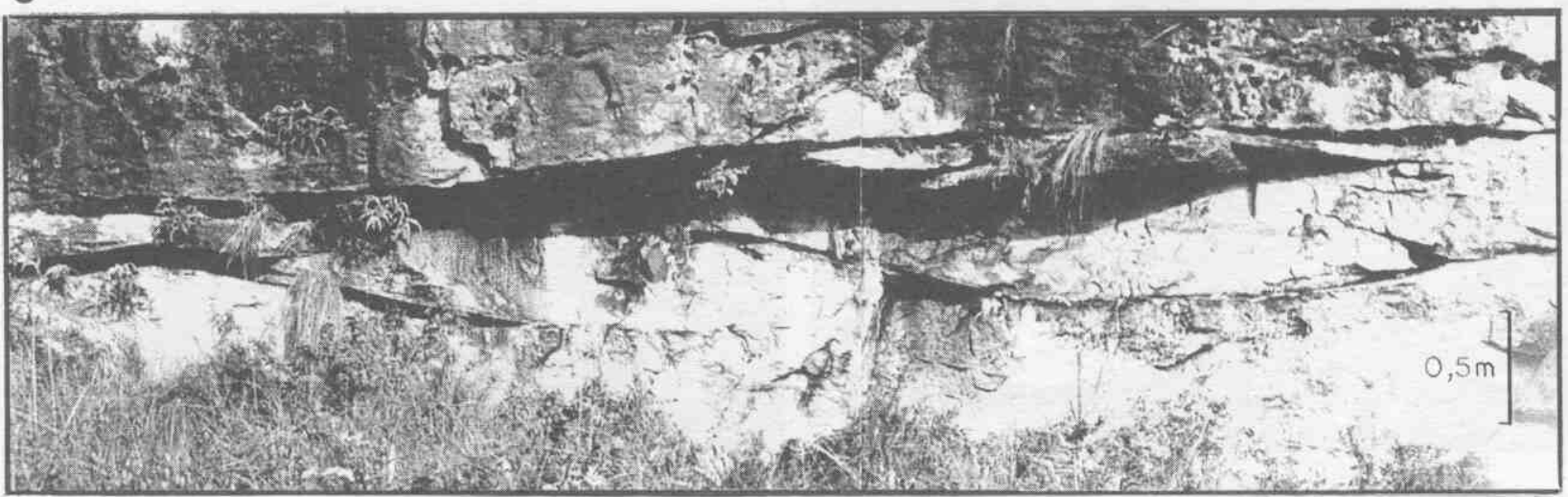

D

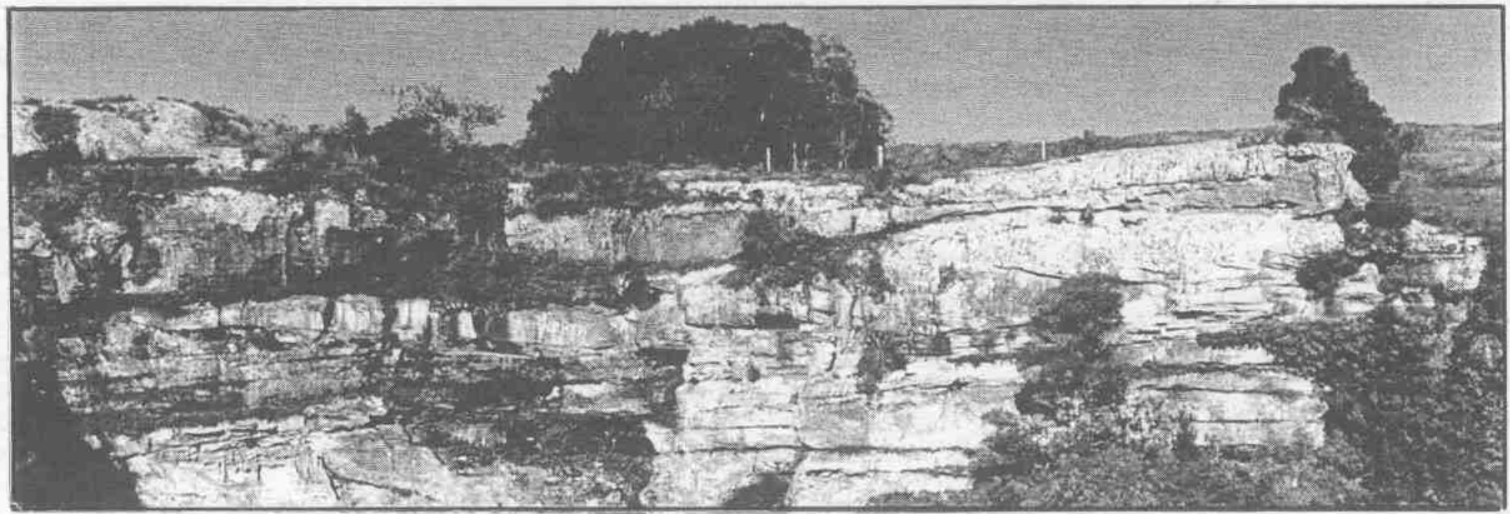

Figura 5 - Unidade média: arenitos com estratificação cruzada planar, às vezes compaleocorrentes de sentidos opostos (A). Quando tangenciais na base, os arenitos gradam para niveis de arenitos finos e siltitos com acamamento ondulado (B). Embora os topos dos seis representem normalmente superficies de reativação, formas de leito, com geometrias sigmóides (C) e espessuras de até $5 \mathrm{~m}$, encontram-se preservadas (D)

nais e muitos exemplos do passado apresentam padrão unimodal e poucas evidências de fluxo no sentido contrário. O padrão unimodal é reflexo de assimetria no fluxo, situação em que as correntes reversas são insuficientemente fortes para transportar sedimentos.

Segundo Klein (1982), marés constituem os processos dominantes em extensas plataformas cratônicas invadidas por águas marinhas durante as transgressões. Correntes de maré têm capacidade de transportar areias muito grossas e até mesmo seixos, que podem se depositar nas camadas frontais dos estratos cruzados ou formar depósitos residuais (Banks 1973, Walker 1985).

Unidade superior $\mathrm{O}$ ambiente foi mais enérgico que na unidade média, o que se reflete na maior granulometria, na pobreza em intercalações sílticas e na existência de pavimentos de seixos (depósitos residuais ou lags). Estes apresentam valores muito altos de razão extensão lateral/espessura, sendo por isso considerados indicadores de processos marinhos rasos, conforme critérios estabelecidos por
Clifton (1973). A geometria planar e a continuidade das superficies de erosão no topo dos coseis, são interpretadas como produto de processos marinhos erosivos, que foram suficientemente competentes para revolver o fundo e transportar areias, mas não frações mais grossas, que ficaram assim concentradas. Este processo de concentração de depósitos residuais pela ação de ondas é conhecido como joeiramento (winnowing).

As paleocorrentes apresentam, em muitos casos, distribuições bipolares oblíquas ou polimodais, sugerindo a atuação de correntes de marés. Valores de variância acima de 4000, indicativos de ambientes marinhos segundo Long \& Young (1978), foram calculados para as distribuições apresentadas.

Um modelo muito interessante para explicar a formação de superfícies planares pavimentadas por seixos foi apresentado por Anderton (1976), tendo sido já aplicado à Formação Furnas por Bergamaschi (1992) e Borghi (1993). O mesmo modelo foi adotado também por 
A

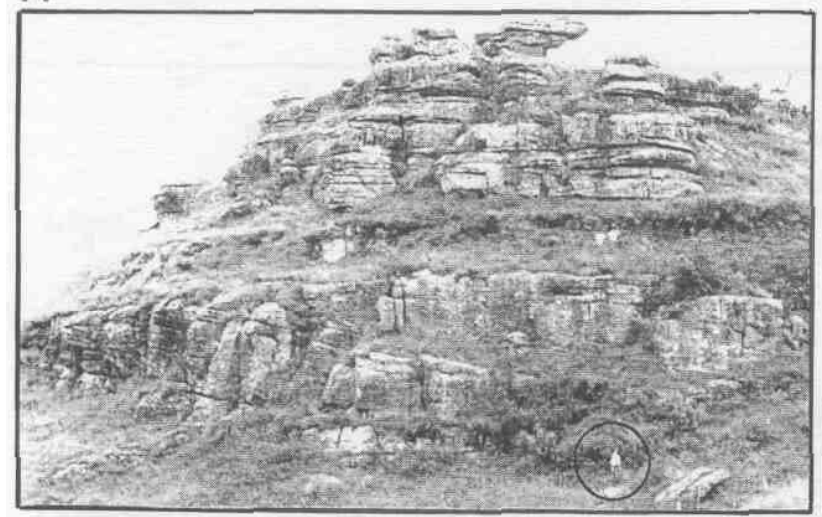

C

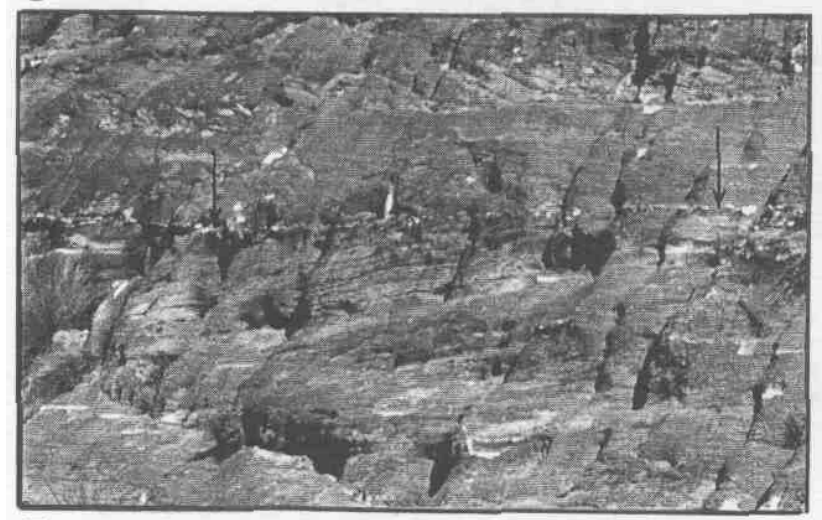

$\mathrm{E}$

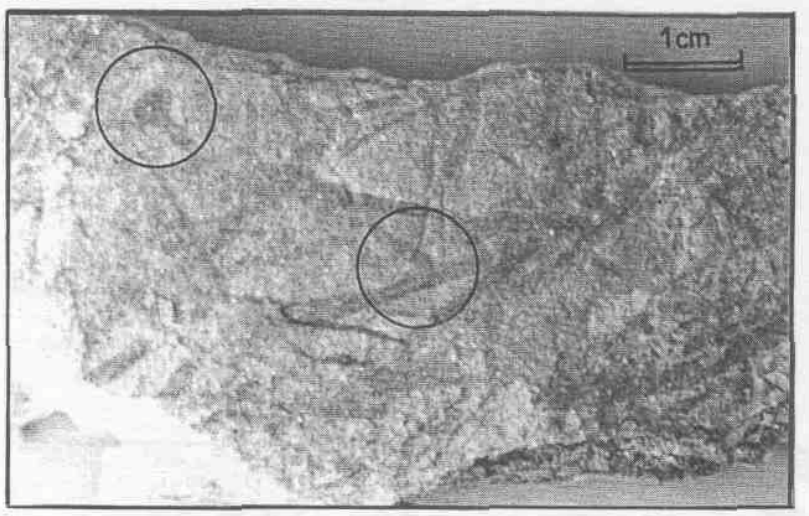

B

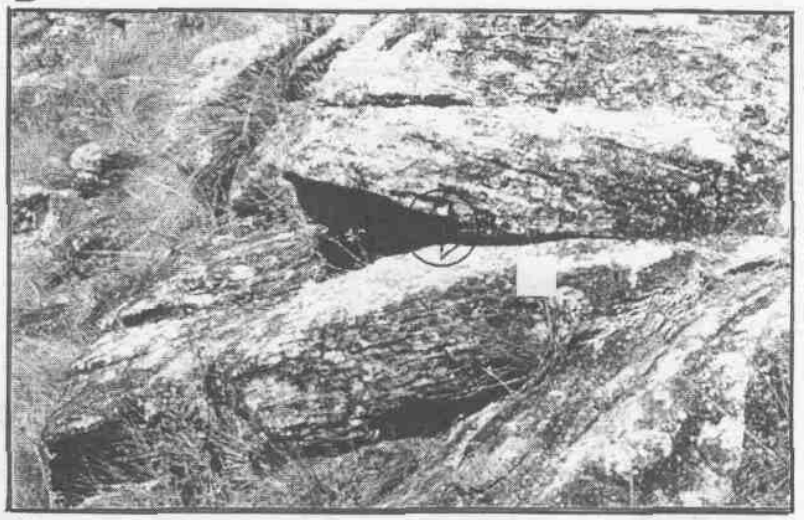

D

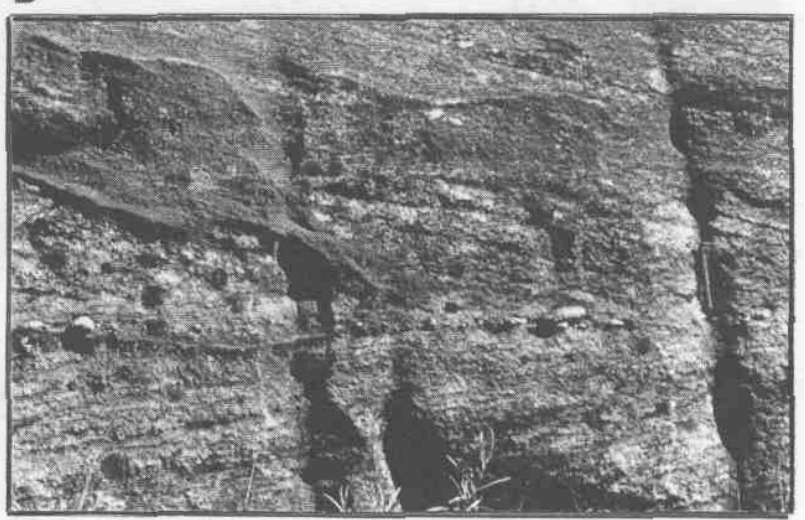

$\mathrm{F}$

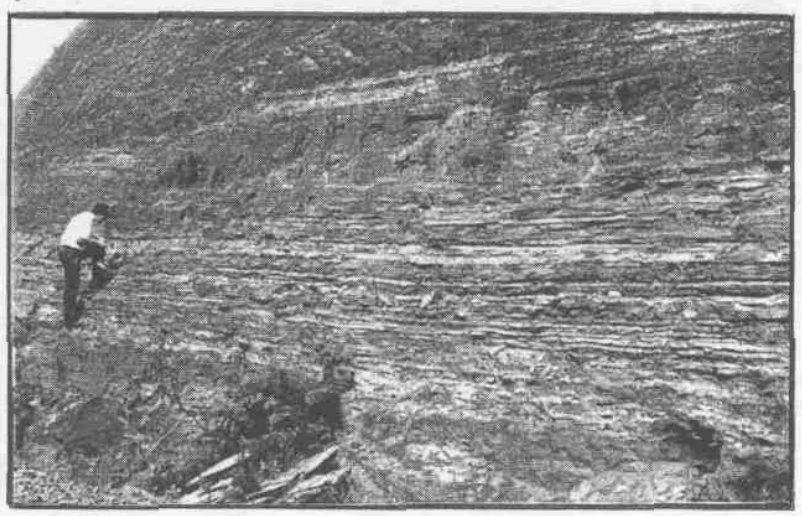

Figura 6 - Unidade superior: A) set de estratificação cruzada com cerca de $7 \mathrm{~m}$ de espessura (no destaque uma figura humana para escala); B) estratificação cruzada espinha-de-peixe; C) superficie planar entre camadas com estratos cruzados, pavimentadas por seixos (indicada por setas); D) detalhe dos pavimentos de seixos; E) vegetais vasculares primitivo (provavelmente de Cooksonia), observando-se nos destaques um esporângio (esquerda) e um talo dicotômico; F) intercalação de fácies heterolíticas portadores de palinomorfos

Richards (1986) em estudo sobre o Triássico Inferior dos Alpes, para explicar superficies de erosão marinha com seixos, lateralmente persistentes por mais de $8 \mathrm{~km}$.

O modelo baseia-se na distribuição de diferentes formas de leito em seis zonas alinhadas no sentido das correntes de maré. As superfícies planares de abrasão marinha são produzidas pelo aumento da amplitude das ondas durante eventos episódicos relacionados a tempestades, que causam remobilização dos sedimentos de fundo, carreamento das partículas menores pelas correntes e queda dos clastos maiores após a passagem das ondas, num processo de joeiramento que resulta na pavimentação do fundo por seixos e calhaus (Fig. 12).

Intercalações de arenitos muito finos e pelitos, algumas vezes exibindo estratificação cruzada hummocky, ocorrem próximo ao topo da unidade. Nestes níveis, em muitas localidades ocorrem vegetais vasculares primitivos (Mussa et al. 1996) e palinomorfos do Praguiano (Dino \& Rodrigues 1995). O empilhamento é transgressivo, havendo incremento de fácies geradas pela atuação de ondas, o que se manifesta plenamente nas Camadas de Transição no topo da Formação Furnas.
CONSIDERAÇÕES FINAIS A correlação apresentada na figura 13 mostra que há uma boa correspondência entre as unidades descritas em superfície no flanco sudeste da bacia e assinaturas características em perfis de raios-gama de poços no Estado do Paraná, o que torna viável a subdivisão da Formação Furnas em subsuperfície e a interpretação das associações faciológicas a partir dos perfis de raios-gama. Mais que isso, por apresentarem posição estratigráfica definida e serem reconhecidas regionalmente, as unidades identificadas correspondem à hierarquia de membros na nomenclatura litoestratigráfica.

A unidade inferior é caracterizada por valores baixos de radioatividade, compatível com fácies areno-conglomeráticas em que há pobreza em argila. A unidade média apresenta arenitos com valores mais altos de radioatividade, indicativos de maior argilosidade, e um padrão serrilhado em perfis de raios-gama com inúmeros picos de maior radioatividade devido à presença de intercalações sfltico-argilosas. A unidade superior caracteriza-se por valores muito baixos de radioatividade e padrões em caixa nos perfis de raios-gama. A passagem da 


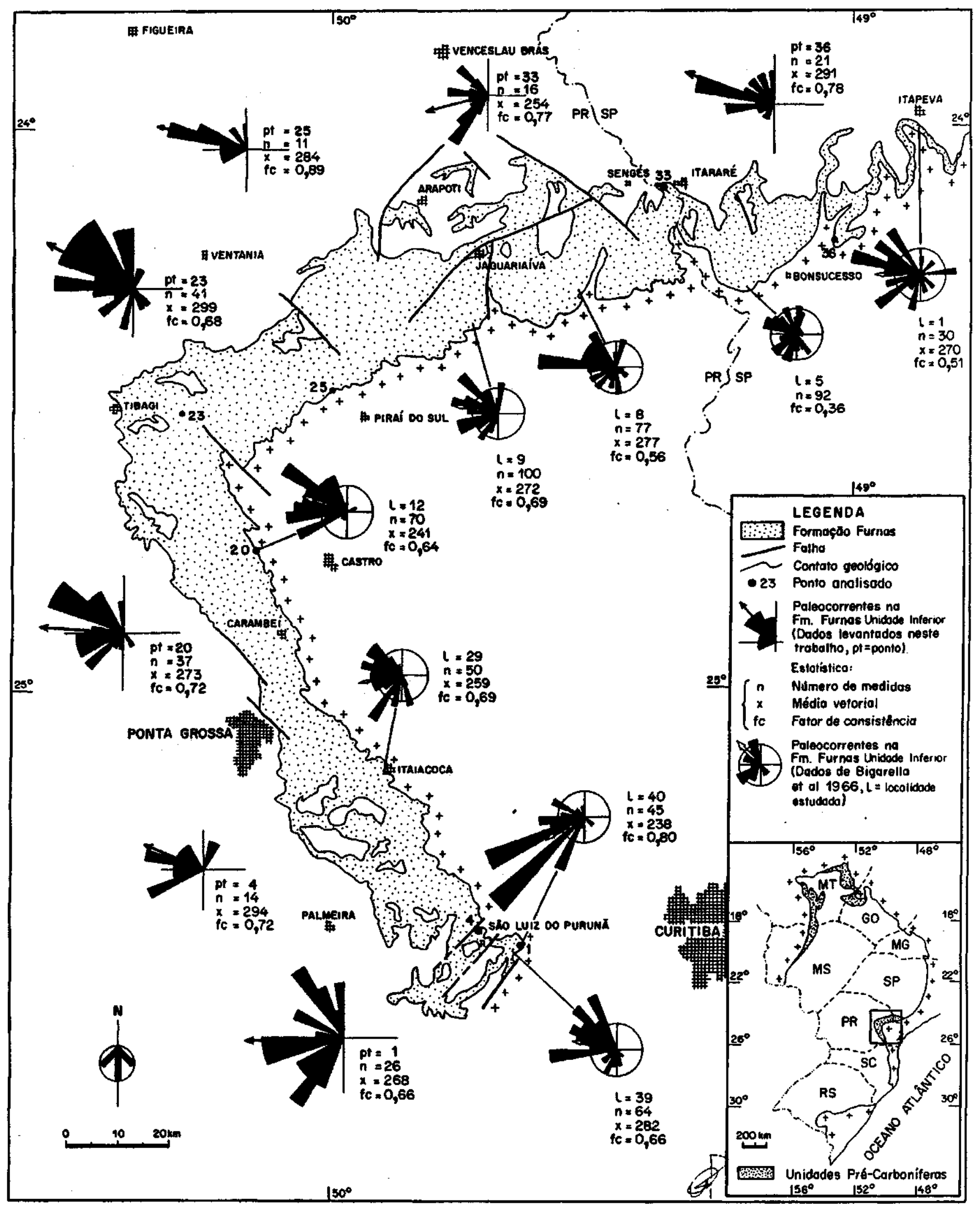




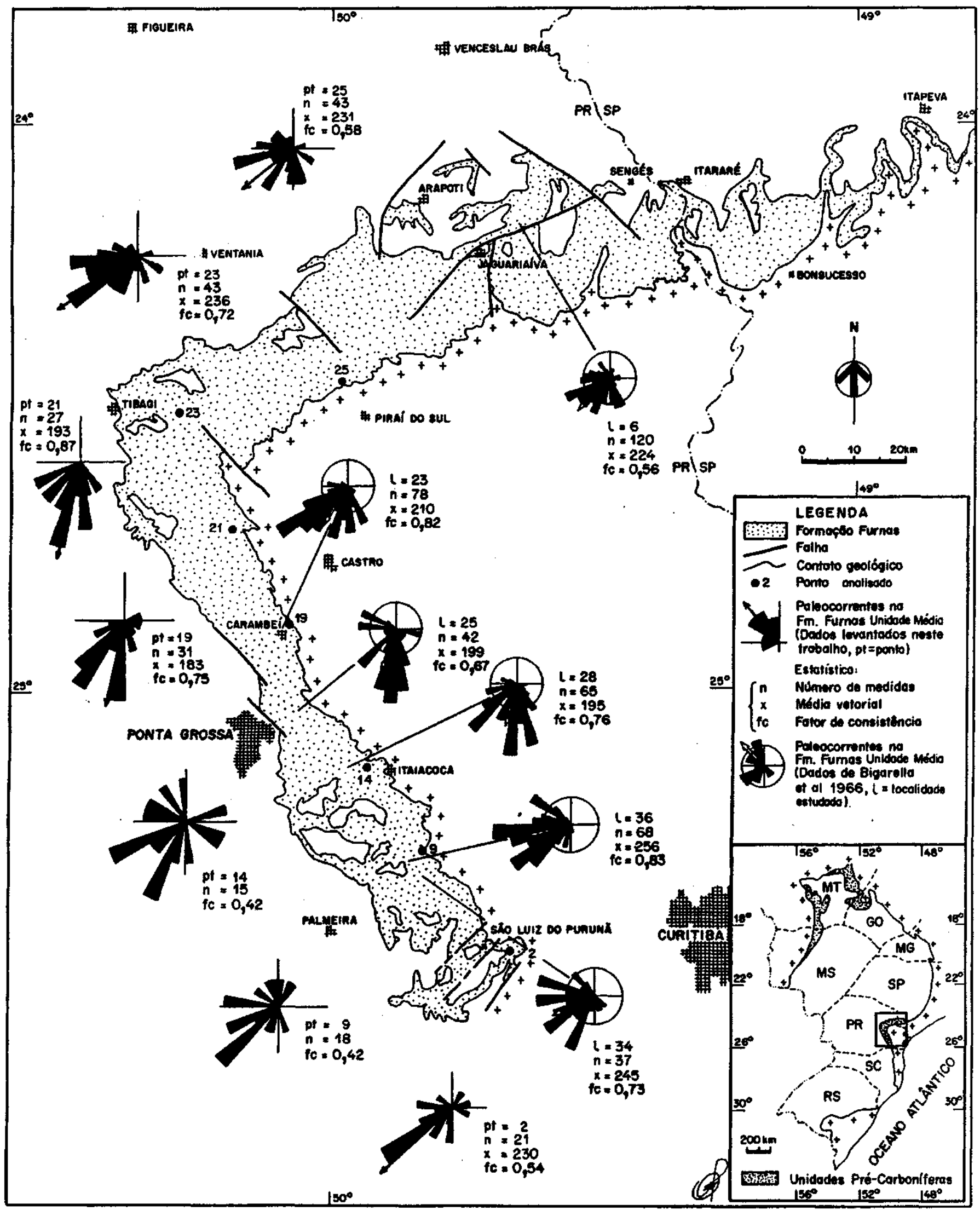

Figura 8- Padrão de paleocorrentes para sudoeste nas fácies marinhas plataformais da unidade média (vetor médio 218) 


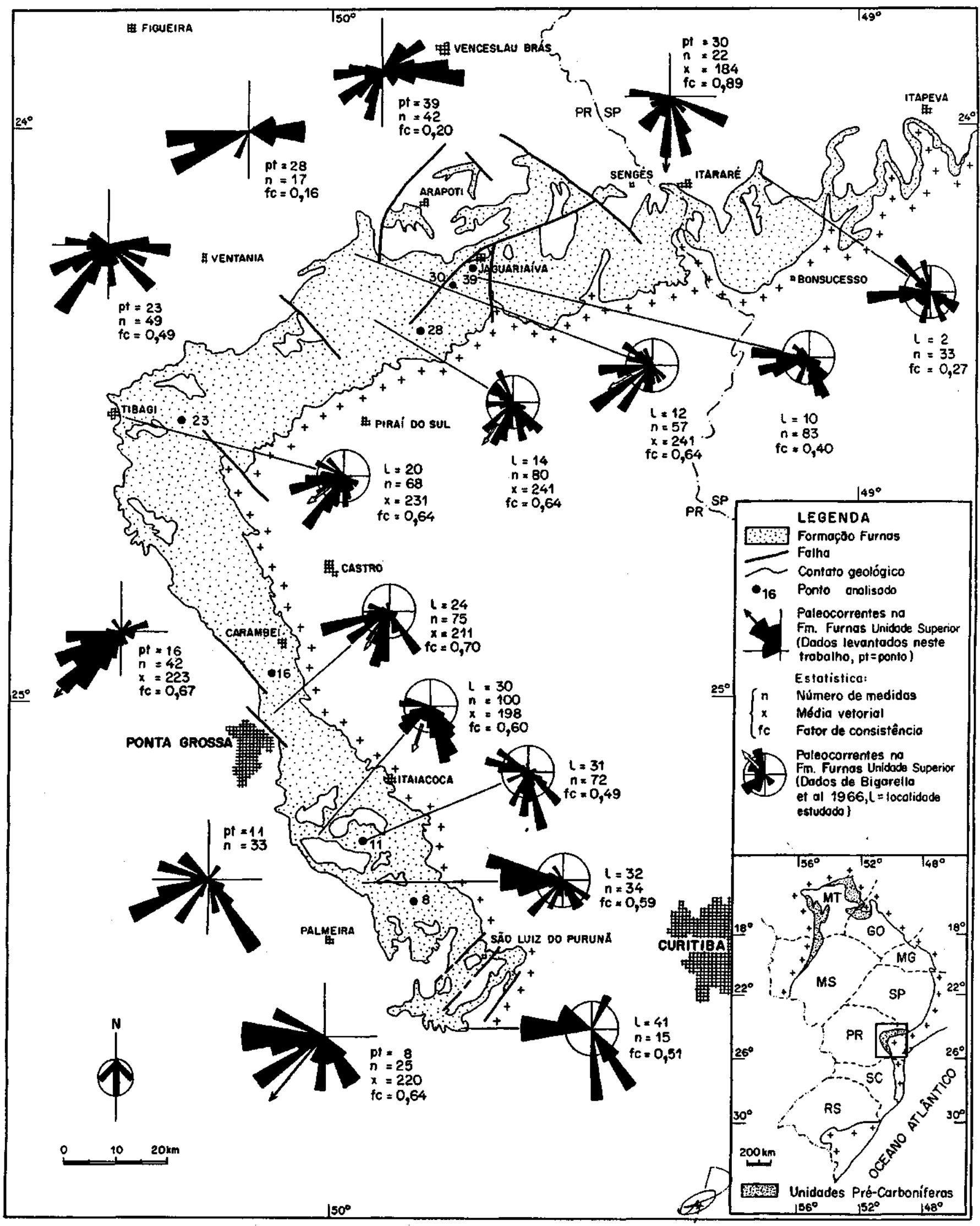

Figura 9 - Padrão bimodal (bipolar) a polimodal de paleocorrentes nas fácies marinhas costeiras a plataformais, dominadas por marés e influenciadas por ondas, da unidade superior 
A

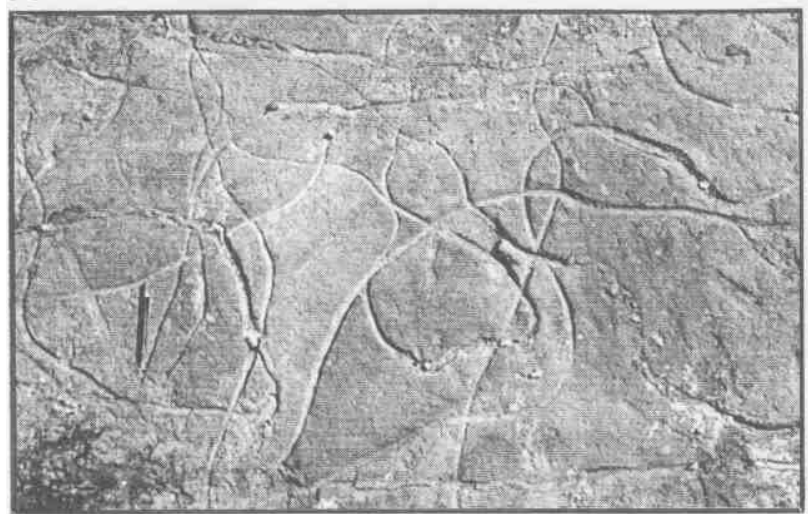

C

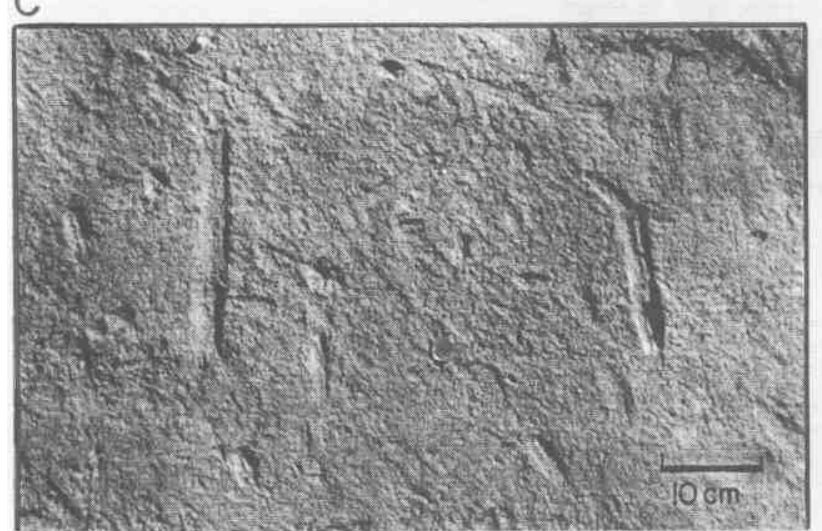

E

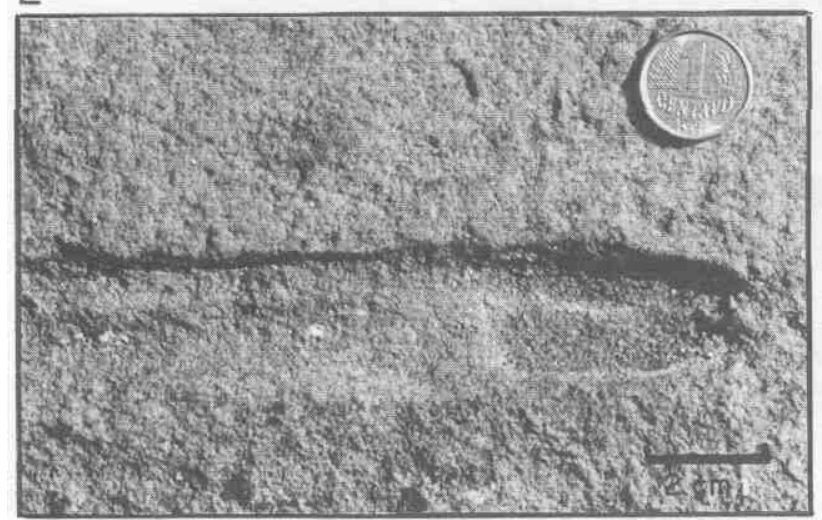

Figura 10 - Associação de icnofósseis presente no afloramento $n^{\circ} 2$, situado nas margens da BR-277: A) superficie de topo de arenitos com estratificação cruzada, onde podem ser identificados diversos tipos de icnofósseis; B) Rusophycus; C) Rusophycus e Cruziana; D e E) continuidade entre os traços Rusophycus e Cruziana, indicando que foram produzidos pelo mesmo organismo; F) Cruziana

unidade média para a superior é marcada por brusco deslocamento da curva para a esquerda, indicando diminuição da argilosidade na unidade superior. Fácies conglomeráticas foram descritas nos poços 2MO-1-PR e 1-MO-2-PR, sendo correlacionadas com os pavimentos de seixos descritos na unidade superior da seção do Guartelá. Para o topo, a Formação Furnas apresenta, paulatinamente, mais e mais intercalações pelíticas, delineando um padrão geral de granodecrescência, com deflexão à direita nos perfis de raios-gama em direção aos folhe-lhos marinhos da Formação Ponta Grossa. A passagem gradual entre as duas unidades é materializada pelas Camadas de Transição no topo da Formação Furnas.

$\mathrm{Na}$ seção estratigráfica apresentada na figura 13 pode-se observar também um incremento de argilosidade para oeste nos perfis de raios-gama, o que é coerente com paleomergulho deposicional para
B
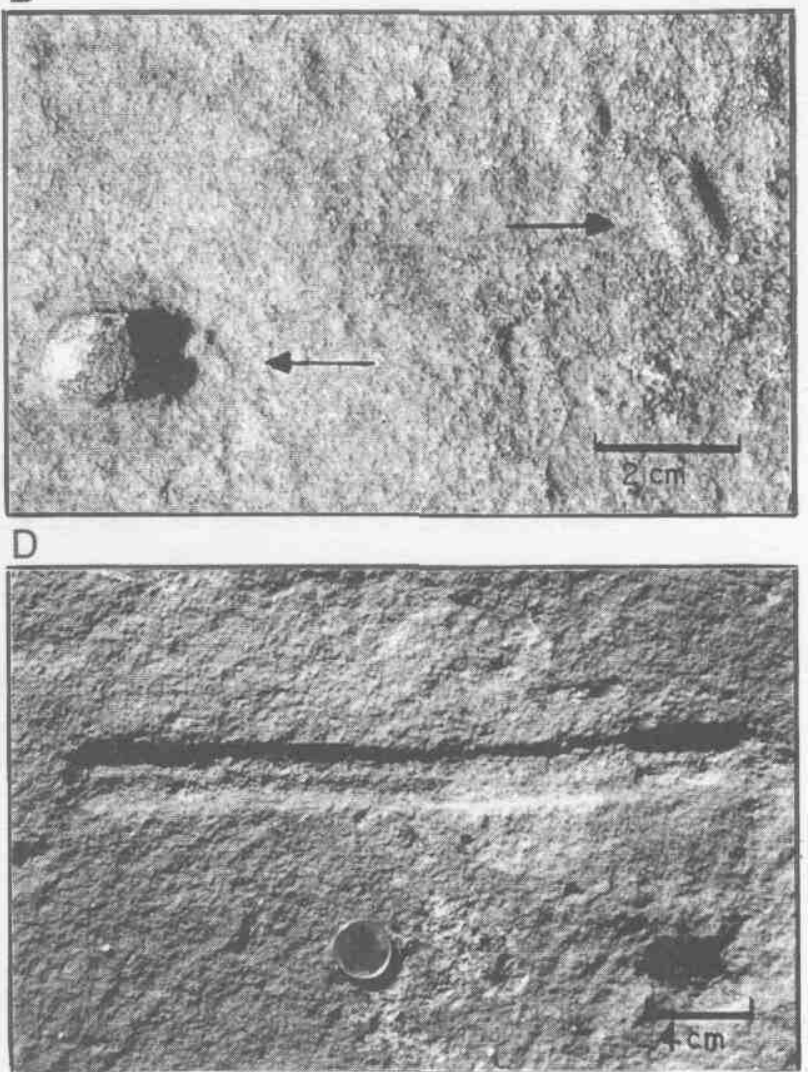

$\mathrm{F}$
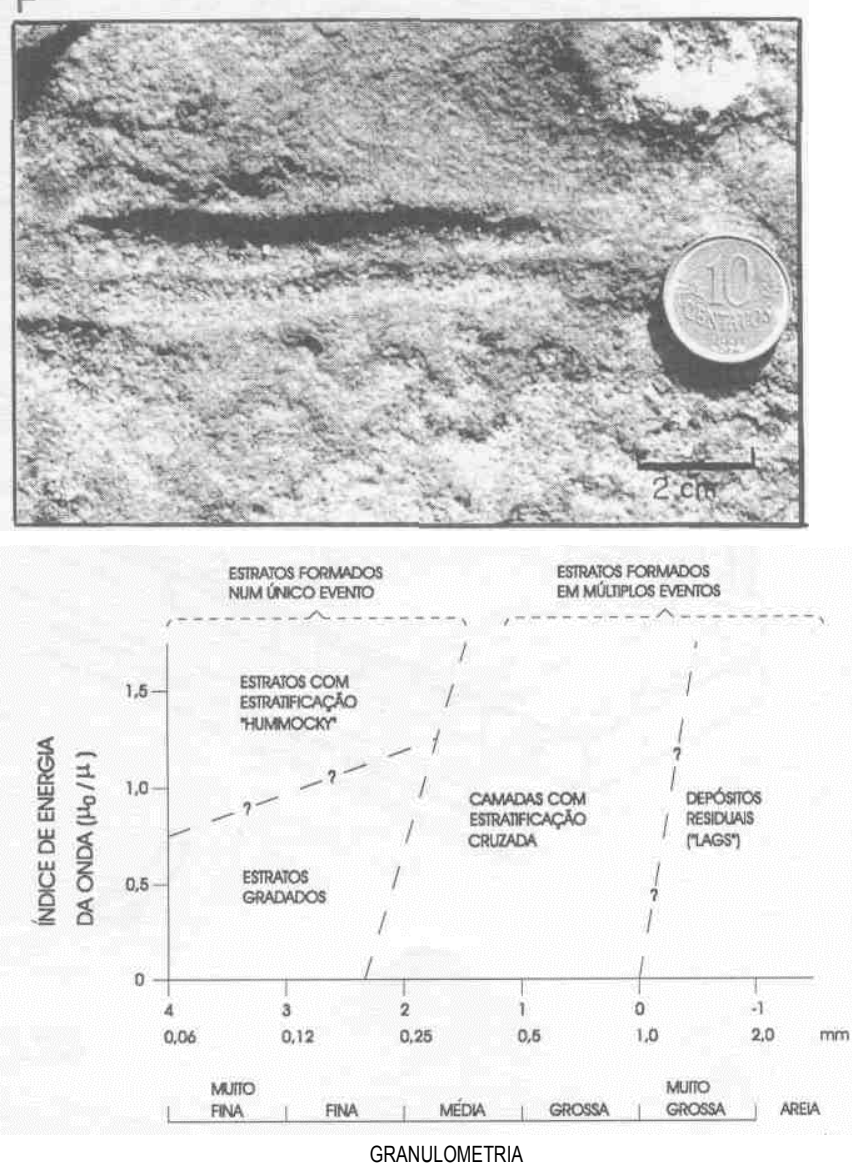

Figura 11 - Estruturas sedimentares geradas pela ação de ondas em função da energia das ondas e de substratos com diferentes granulometrias (Swift et al 1986) ( $\mu_{o}=$ velocidade orbital máxima da onda; $\mu=$ velocidade média de propagação) 


\begin{tabular}{|c|c|c|c|c|c|c|}
\hline ZONAS: & 6 & 5 & 4 & 3 & 2 & 1 \\
\hline
\end{tabular}

I - CONDIÇÕES DE TEMPO BOM: correntes de marés normais II - CONDIÇOESS DE TEMPESTADES MODERADAS: correntes de maré de intensificadas por ondas

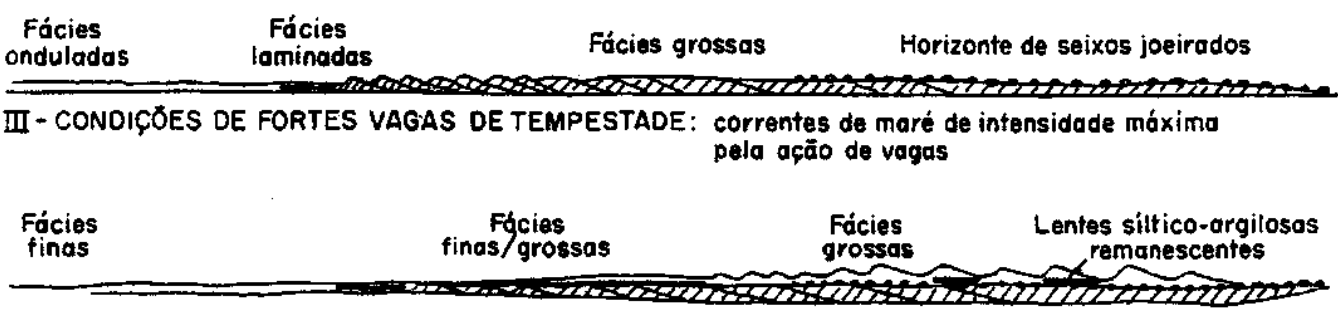

IV-RETORNO ÀS CONDIÇŌES DE TEMPO BOM: correntas do marés normais

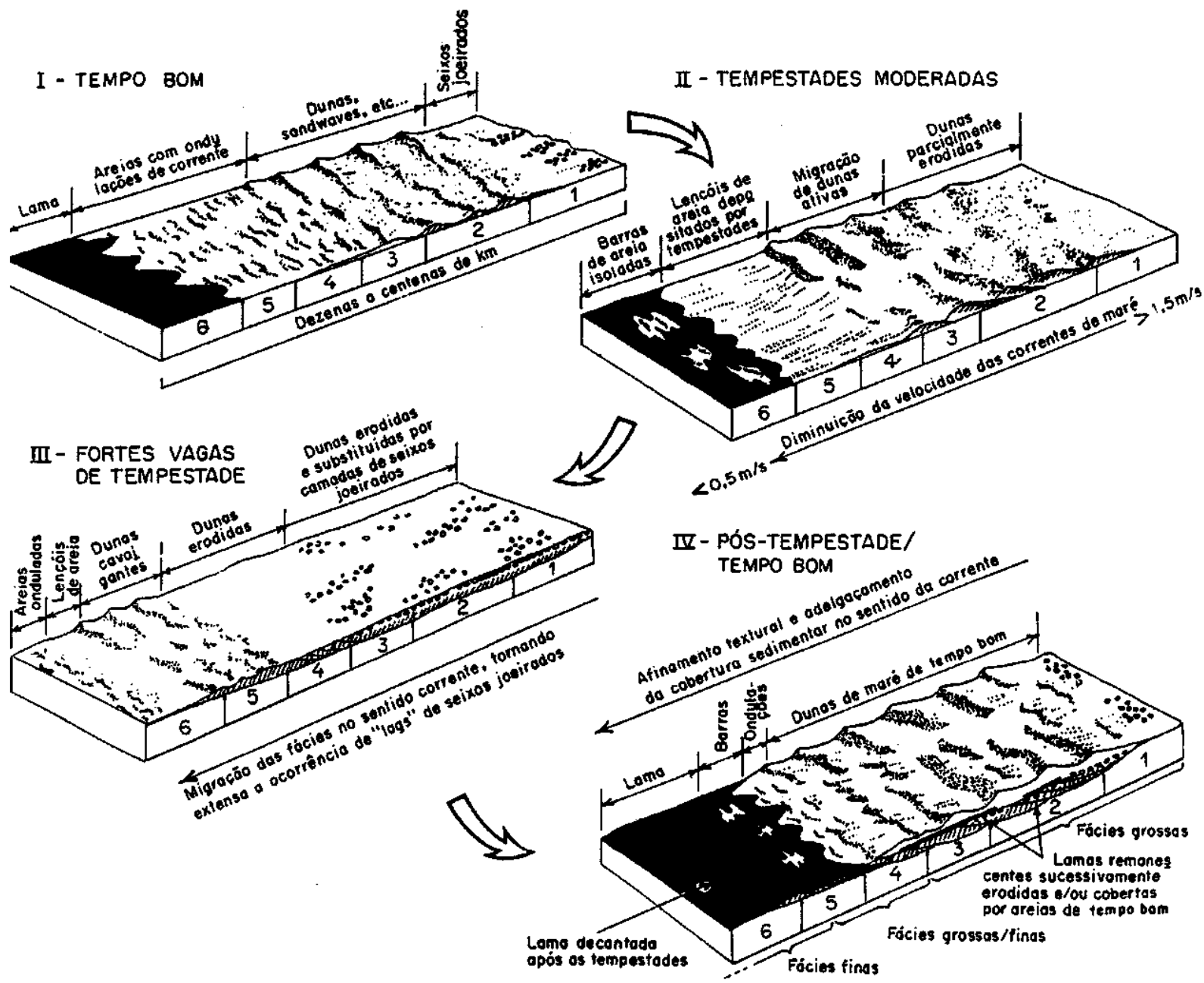

Figura 12 - Mecanismo deformação de depósitos residuais de seixos (lags) em ambientes marinhos rasos (baseado em Anderton 1976, com modificações introduzidas por Richards 1986 e Johnson \& Baldwin 1996). São mostradas as formas de leito e estruturas sedimentares geradas numa plataforma arenosa rasa dominada por correntes de maré, episodicamente afetada por fortes ondas de tempestade que promovem retrabalhamento do fundo, com joeiramento (winnowing) dos sedimentos e formação de pavimentos de seixos. 


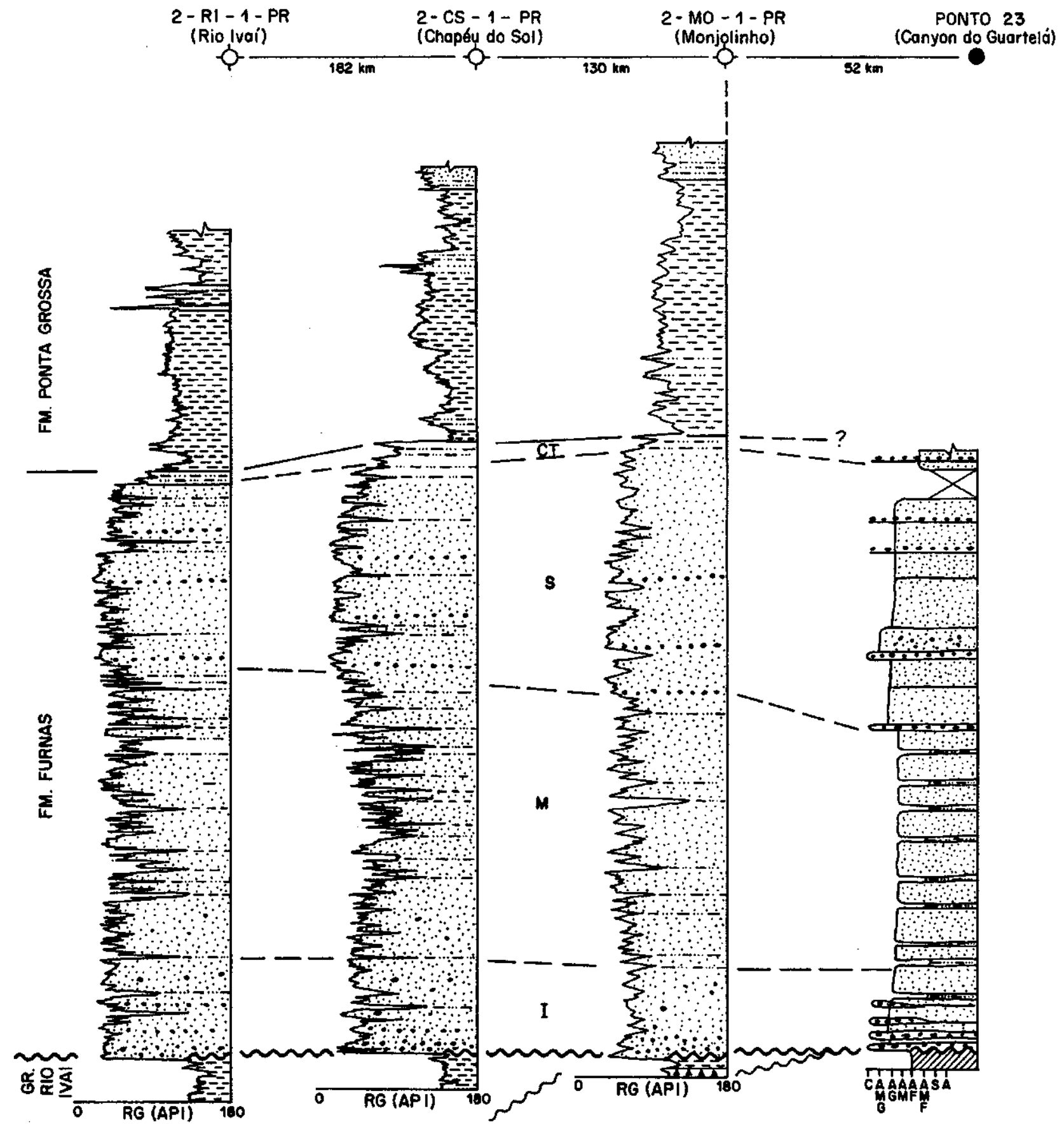

\begin{tabular}{|c|c|c|c|c|}
\hline SU: & BOIVISĀO D & Fm. FURNAS: & $==-$ & Folhelho \\
\hline CT & $=$ Camadas & le Transiçāo & & Siltito \\
\hline $\mathbf{s}$ & = Unidode & superior & & Arenito \\
\hline $\mathbf{M}$ & - Unidade & médio & $\because$ & Conglomerodo \\
\hline I & = Unidade & inferior & & Diamictito \\
\hline
\end{tabular}

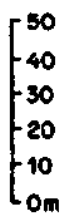

$\left[\begin{array}{l}50 \\ -40 \\ -30 \\ -20 \\ -10 \\ 0 m\end{array}\right.$

Obs.: Dtabásios foram retirados dos perfis

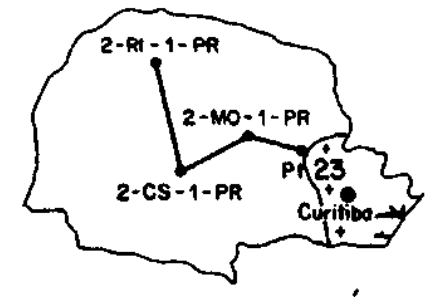

ESTADO DO PARANÁ

Figura 13 - Correlação do perfil vertical levantado no canyon do Guartela com perfis raios-gama de poços 
oeste e área-fonte a leste, deduzidos através das paleocorrentes das fácies de planícies aluviais costeiras da unidade inferior.

Por último, destaca-se que o empilhamento estratigráfico observado no flanco sudeste da Bacia do Paraná não constitui registro de contexto paleogeográfico de borda de bacia. Porções proximais do trato deposicional da Formação Furnas foram parcialmente erodidas já no Eocarbonífero, com o levantamento da região leste do Estado do Paraná (Assine 1996), quando tectônica modificadora e flutuações climáticas alteraram o nível de base de erosão gerando a discordância que separa as unidades devonianas do Grupo Paraná das unidades carboníferas do Grupo Itararé. O levantamento posterior do Arco de
Ponta Grossa no Mesozóico causou nova erosão das porções proximais da Formação Furnas, sendo responsável pela forma atual, em lua crescente, da faixa de afloramentos da Formação Furnas no flanco sudeste da Bacia do Paraná.

Agradecimentos Ao Prof. Setembrino Petri pelo estímulo e apoio à realização deste trabalho; aos colegas Paulo S. Gomes Paim e Renata Guimarães Netto pela leitura crítica e sugestões; à FAPESP pelo apoio à pesquisa (proc. 98/2183-3); à Petrobrás pela autorização para publicação de perfis de poços; aos desenhistas Oto Laurentino Rosa e António Cezário Porta Jr. pelas ilustrações.

\section{Referências}

Anderton R. 1976. Tidal-shelf sedimentation: an example from the Scottish Dalradian. Sedimentology, 23:429-458.

Andrade S.M. \& Camarço P.E.N. 1980. Estratigrafia dos sedimentos devonianos do flanco nordeste da Bacia do Paraná. In: Congresso Brasileiro de Geologia, 31. Camboriú, 1980. Anais... Camboriú, SBG. v. 5, p. 2828-2836.

Assine M. L. 1996. Aspectos da estratigrafia das sequências pré-carboniferas da Bacia do Paraná no Brasil. Instituto de Geociências, Universidade de São Paulo, São Paulo, Tese de Doutoramento, 207p.

Assine M.L. \& Gois J.R. 1996. Traços fósseis de trilobita na Formação Furnas, Bacia do Paraná, Brasil. In: Simpósio Sul Americano do Siluro-Devoniano, Ponta Grossa, p.371-373.

Assine M. L., Soares P. C., Milani E. J, 1994. Sequências tectono-sedimentares mesopaleozóicas da Bacia do Paraná, Sul do Brasil. Revista Brasileira de Geociências, 24:77-89.

Banks N.L. 1973. Tide-dominated offshore sedimentation, Lower Cambrian, north Norway. Sedimentology, 20:213-228.

Bergamaschi S. 1992. Análise sedimentológica da Formação Furnas na faixa de afloramentos do flanco norte do arco estrutural de Ponta Grossa, Bacia do Paraná, Brasil. Instituto de Geociências, Universidade Federal do Rio de Janeiro, Rio de Janeiro, Dissertação de Mestrado, 172p.

Berne S., Lericolais G., Marsset T., Bourillet F., Batist M. 1998. Erosional offshore sand ridges and lowstand shorefaces: examples from tide- and wave-dominated environments of France. Journal of Sedimentary Research, 68:540-555.

B igarella J. J. 1973. Paleocorrentes e deriva continental (comparação entre África e América do Sul). Boletim Paranaense de Geociências, 31:141-224.

Bigarella J. J. \& Salamuni R. 1967. Some palaeogeographic features of the Brazilian Devonian. In: Bigarella J. J. (ed.) Problems in Brazilian Devonian Geology. Boletim Paranaense de Geociências., 21/22:133-151.

Bigarella J.J., Salamuni R., Marques P.L..P 1966. Estruturas e texturas da Formação Furnas e sua significação paleogeográfica. Boletim da UFPR (Geologia) 18:1-114.

Borghi L. 1993. Caracterização e análise faciológicas da Formação Furnas (Prídoli Devoniano inferior) em afloramentos do bordo leste da bacia sedimentar do Paraná, Estado do Paraná, Brasil. Instituto de Geociências, Universidade Federal do Rio de Janeiro, Rio de Janeiro, Dissertação de Mestrado, 227p

Borghi L. \& Schubert G. 1992. Furnasichnus langei, ichnog. et ichnosp. nov., and its relation to other trace fossils from the Devonian of Paraná State, Brazil. Anais da Academia Brasileira de Ciências, 64:418.

Chandler F.W. 1988. Quartz arenites: review and interpretation. Sedimentary Geology, 58:105-126.

Ciguel J. H. G. \& Acenolaza F. G. 1986. Icnologia da Formação Furnas (Paleozóico médio), Bacia do Paraná. Anais da Academia Brasileira de Ciências, 58:595-596

Ciguel J.H.G. \& Aceftolaza F.G. 1991. Icnologia da Formação Furnas (Paleozóico Médio), Bacia do Paraná. Revista Técnica de YPFB, 12(1): 145.

Clifton H. E. 1973. Pebble segregation and bed lenticularity in wave-worked versus alluvial gravei. Sedimentology, 20:173-187.

Dino R. \& Rodrigues M. A. C. 1995. Palinomorfos eodevonianos da Formação Furnas Bacia do Paraná. Anais da Academia Brasileira de Ciências, 67:107-116.

Duke W.L. 1990. Geostrophic circulation or shallow marine turbidity currents? The dilemma of paleoflow patterns in storm-influenced prograding shoreline systems. Journal of Sedimentary Petrology, 60:870-883.

Fernandes A.C.S. 1996. Os icnofósseis do Ordoviciano, Siluriano e Devoniano da Bacia do Paraná. Instituto de Geociências, Universidade Federal do Rio de Janeiro, Rio de Janeiro, Tese de Doutoramento, 183p.

Fernandes A.C.S. \& Netto R. G. 1985. O estado atual da paleoicnologia no Paleozóico da Bacia do Paraná. In: Congresso Brasileiro de Paleontologia, 9, Fortaleza, 1985. Resumos das Comunicações... Fortaleza, SBP, p. 41.

Frey R. W. \& Pemberton S. G. 1984. Trace fóssil fácies models. In: Walker R. G. (ed.) Fácies models. $2^{\mathrm{a}}$ ed. Toronto, Geoscience Canada (Reprint Series 1), p. 189-207.

Hayes M.0.1967. Relationship between coastal climate and bottom sediment type on the inner continental shelf. Marine Geology., 5:111-132.

Johnson H.D. \& Baldwin C.T. 1996. Shallow clastic seas. In: Reading H.G. (ed), Sedimentary environments: Processes, Fácies and Stratigraphy. Oxford, Blackwell Science, p. 232-280.

Klein G. deV. 1982. Probable sequential arrangement of depositional systems on cratons. Geology, 10:17-22

Lange F.W. 1942. Restos vermiformes do Arenito das Furnas. Arquivos do Museu Paranaense, 2:2-18.
Lange F.W. \& Petri S. 1967. The Devonian of the Paraná Basin. In: Bigarella J. J. (ed.) Problems in Brazilian Devonian Geology. . Boletim Paranaense de Geociências, 21/22:5-55.

Long D.G.F. \& Young G.M. 1978. Dispersion of cross-stratification as apotential tool in the interpretation of Proterozoic arenites. Journal of Sedimentary Petrology, 48:857-862.

Maack R. 1950-51. Vestígios pré-devonianos de glaciação e a sequência de camadas devonianas no Estado do Paraná. Curitiba, Arquivos de Biologia e Tecnologia (IBPT), V-VI: 197-230.

Melo J.H.G. 1988. The malvinokaffric realm in the Devonian of Brazil. In: McMillan N. J., Embry A.F., Glass D.J. (eds.) Devonian of the world. Canadian Society of Petroleum Geologists (Memoir 14), p. 669-703.

Mussa D., Borghi L., Bergamaschi S., Schubert G., Pereira E., Rodrigues M. A. C.1996. Estudo preliminar da tafoflora da Formação Furnas, Bacia do Paraná, Brasil. Anais da Academia Brasileira de Ciências, 68:65-89.

Nemec W. \& Steel RJ. 1984. Alluvial and coastal conglomerates: their significam features and some comments on gravelly mass-flow deposits. In: Koster E. H. \& Steel R. J. (eds.). Sedimentology of graveis and conglomerates. Canadian Society of Petroleum Geologists (Memoir 10), p. 1-31.

Northfleet A. A., Medeiros R. A., Mühlmann H. 1969. Reavaliação dos dados geológicos da Bacia do Paraná. Boletim. Técnico da Petrobrás, 12(3):291-346.

Odin G.S. 1982. The Phanerozoic time scale revisited. Episodes, 3:3-9.

Petri S. 1948. Contribuição ao estudo do Devoniano paranaense. Rio de Janeiro, DNPM/DGM, 125p. (Boletim 129).

Petri S. \& Fulfaro V.J. 1983. Geologia do Brasil (Fanerozóico). São Paulo, T.A.Queiroz/EDUSP, 631p.

Phillips R. L. 1984. Depositional features of Late Miocene, marine cross-bedded conglomerates, Califórnia. In: Koster E. H. \& Steel R. J. (eds.). Sedimentology of graveis and conglomerates. Canadian Society of Petroleum Geologists (Memoir $10)$, p. 345-358.

Richards M.T. 1986. Tidal bed form migration in shallow marine environments: evidence from the Lower Triassic, Western Alps, France. In: Knight R.J. \& McLean J.R. (eds.). Shelf sands and sandstones. Canadian Society of Petroleum Geologists (Memoir 11), p.257-276.

Sanford R. M. \& Lange F. W. 1960. Basin study approach to oil evaluation of Paraná miogeosyncline, south Brazil. American Association of Petroleum Geologists flw/fetin, 44:1316-1370.

Schneider R.L., Mühlmann H., Tommasi E., Medeiros R.A., Daemon R.F., Nogueira A. A. 1974. Revisão estratigráfica da Bacia do Paraná. In: Congresso Brasileiro de Geologia, 28. Porto Alegre, 1974. Anais... Porto Alegre, SBG. v. 1, p. 41-65.

Selley R.C. 1982. Introduciion to Sedimentology. $2 *$ ed., Londres, Academic Press, 417p.

Swift D. J. P.\& Thorne J. A. 1991 .Sedimentation on continental margins, I: a general mode for shelf sedimentation. In: Swift D. J. P., Oertel G.F., Tillman R. W., Thorne J. A. (eds.). Shelf sand and sandstone bodies: geometry, fácies and sequence Stratigraphy. Oxford, Blackwell Sci./IAS (Sp. Publ. 14), p. 3-31.

Swift D.J.P., Thorne J.A., Oertel G.F. 1986. Fluid processes and sea-floor response on a modern storm-dominated shelf: middle Atlantic shelf of North America. Part II: response of the shelf floor. In: Knight R.J. \& McLean J.R. (eds.) Shelf sands and sandstones. Canadian Society of Petroleum Geologists (Memoir 11), p. 191-211.

Swift D. J. P., Phillips S., Thorne J. A. 1991. Sedimentation on continental margins, IV: lithofacies and depositional systems. In: Swift D. J. P., Oertel G.F., Tillman R. W., Thome J. A. (eds.). Shelf sand and sandstone bodies: geometry, fácies and sequence Stratigraphy. Oxford, Blackwell Sci./IAS (Sp. Publ. 14), p. 89-152.

Van Houten F.B. \& Purucker M.E. 1984. Glauconitic paloids and chamositic ooids favorable factors, constraints and problems. Earth-Science Reviews, 20:211-243.

Walker R. G. 1985. Ancient examples of tidal sand bodies formed in open, shallow seas. In: Tillman R.W., Swift D. J. P., Walker R.G. (eds.) Shelf sands and sandstone reservoirs. Tulsa, Society for Sedimentary Geology (SEPM, Short course 13), p. 303-341.

Zalán P.V., Wolff S., Conceição J.C.J., Vieira I.S., Astolfi M.A.M., Appi V.T., Zanotto O. A. 1987a. A divisão tripartite do Siluriano da Bacia do Paraná. Revista Brasileira de Geociências, 17:242-252. 